Portland State University

PDXScholar

$1-1-2010$

\title{
Thin Film Group II-VI Solar Cells Based on Band- Offsets
}

James Keith Walton

Portland State University

Follow this and additional works at: https://pdxscholar.library.pdx.edu/open_access_etds

Part of the Physics Commons

Let us know how access to this document benefits you.

\section{Recommended Citation}

Walton, James Keith, "Thin Film Group II-VI Solar Cells Based on Band-Offsets" (2010). Dissertations and Theses. Paper 435.

https://doi.org/10.15760/etd.435

This Thesis is brought to you for free and open access. It has been accepted for inclusion in Dissertations and Theses by an authorized administrator of PDXScholar. Please contact us if we can make this document more accessible: pdxscholar@pdx.edu. 
Thin Film Group II-VI Solar Cells

Based On Band-Offsets

by

James Keith Walton

A thesis submitted in partial fulfillment of the requirements for the degree of

Master Of Science

In

Physics

Thesis Committee:

Rajendra Solanki, Chair

J. L. Freeouf

M. A. K. Khalil

Portland State University

2010 


\begin{abstract}
The amount of traditional energy sources are finite and the ecological impact of continuing to produce energy using fossil fuels will only exacerbate the carbon footprint. It is for these reasons that photovoltaic modules are becoming a larger and more necessary part the world's electricity production paradigm.

Photovoltaic (PV) semiconductor modules are grouped into three categories. 'First generation' monocrystalline and polycrystalline silicon modules that consist of p$\mathrm{n}$ junctions created via the addition of impurities known as dopants. Almost $85 \%$ of solar cells produced at this time are 'first generation' and it is the high production costs of silicon PV modules that motivated the search for new methods and materials to use as PV cells. 'Second generation' PV modules consist of semiconductor thin films. The 'second generation' PV modules in production at this time are copper indium gallium diselenide (CIGS), copper indium gallium (CIG), amorphous silicon (a-Si), and cadmium telluride (CdTe). The ‘third generation' PV modules consist of dye-sensitized and organic materials.

Thin films use less material, have less stringent production parameters and less waste, making thin films cost effective. In this investigation, solar cells were prepared using un-doped Group II-VI semiconductor thin films that exploit differences in bandoffsets to form effective $\mathrm{p}-\mathrm{n}$ heterojunctions as a viable low cost alternative to doping. The thin films were deposited by thermal evaporation upon glass substrates coated with indium tin oxide (ITO). A layer of aluminum formed the back contact. Various
\end{abstract}


configurations of the solar cells were produced including: ITO/CdS/CdSe/Al, ITO/ZnTe/CdSe/Al, ITO/CdTe/CdSe/Al, ITO/ZnTe/CdTe/CdS/Al.

The solar cells produced have been characterized to determine thin film internal resistances, quantum and 'wall-plug' efficiencies, as well as I-V and spectral response. The open circuit voltage, short circuit current density, fill factor, and efficiency of our best devices were $0.26 \mathrm{~V}, 4.6 \mathrm{~mA}, 27.5$ and $0.4 \%$ respectively. Additional device optimization should be possible and should improve these results. Solar cell design based on band-offset is an effective method for predetermining likely PV structures, while future investigation using Group II-VI semiconductor nanowires and nanorods and employing epitaxial films are likely to enhance the efficiency. 


\section{ACKNOWLEDGMENTS}

I would like to thank the following persons and groups for their considerate help.

* Dr. Rajendra Solanki for his advice and guidance in this research. He is a man of great virtue and understanding and none of this would have been possible without his efforts.

* Dr. Gary Goncher for his invaluable help in my data acquisition and analysis. His willingness to miss dinner to work with me and others is indicative of his character.

* Dr. Gary Marks for the articles he made available to me.

* Dr. Keith James and the Wamser Lab for letting me use their acquisition equipment to gather data for my solar cells.

* Dr. Steven Grimes who urged me to continue in physics and pursue a graduate degree.

Dr. Erik Sanchez for providing training on and use of his evaporator.

Dr. John Freeouf for his assistance and good advice and also for the use of his equipment and providing me a desk and office space on campus. 


\section{TABLE OF CONTENTS}

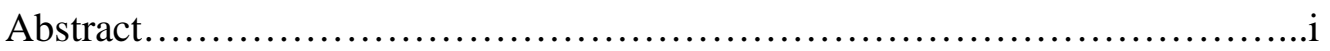

Acknowledgments....................................................ii

List of Tables........................................................ vii

List of

Figures.......................................................viii

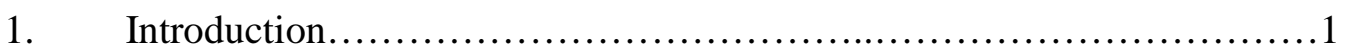

$1.1 \quad$ Energy Issues............................................

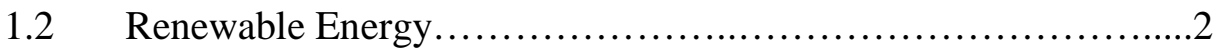

$1.3 \quad$ PV Demand and Cost...........................................

$1.4 \quad$ Types of Solar Cells............................................

$1.5 \quad$ Research Efficiencies......................................6

$1.6 \quad$ Focus of Research..........................................

2. Principles of Photovoltaic Devices...................................8

2.1 Solar Spectrum..........................................8

2.2 Photovoltaic Solar Cells......................................

2.2.1 The $p-n$ Junction..................................... 9

2.2.2 The Un-doped Heterojunction .......................10

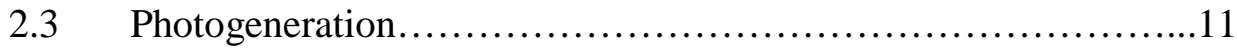

$2.4 \quad$ Recombination............................................13

2.4.1 Band-to-Band Recombination..........................13

2.4.2 Impurity Trap Recombination.........................13

2.4.3 Surface Recombination................................. 14 
2.5 Drift and Diffusivity....................................15

2.6 Device Characterization..................................... 17

2.6.1 Equivalent Circuit...................................17

2.6.2 Current-Voltage Characteristics.......................17

2.6.3 Parasitic Resistances.................................18

2.6.4 Efficiency..........................................19

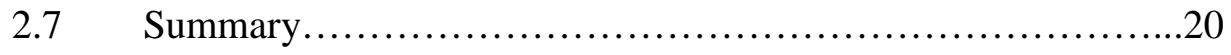

3. Experiment: Materials and Methods................................22

3.1 Materials..................................................22

3.2 Experimental Setup for Thin Film Deposition..................22

3.3 Thin Film Deposition Method.................................24

3.4 Deposition Details.........................................24

3.4.1 ITO/CdS/CdSe/Al Devices...........................24

3.4.2 ITO/ZnTe/CdSe/Al Devices...........................25

3.4.3 ITO/CdTe/CdSe/Al Devices..........................25

3.4.4 ITO/ZnTe/CdTe/CdS/Al Devices.......................26

3.4.5 Thickness of the Thin Films............................27

3.5 Device Characterization.....................................27

3.5.1 I-V Measurements................................27

4. Results and Discussion..........................................29

4.1 ITO/CdS/CdSe/Al Devices..................................29

4.1.1 Band Structure......................................29 
4.1.2 Current-Voltage Curves.................................30

4.1.3 Tabulated Results.........................................30

4.1.4 Discussion............................................ 31

4.2 ITO/ZnTe/CdSe/A1 Devices...............................32

4.2.1 Band Structure........................................32

4.2.2 Current-Voltage Curves................................33

4.2.3 Tabulated Results....................................33

4.2.4 Discussion......................................... 34

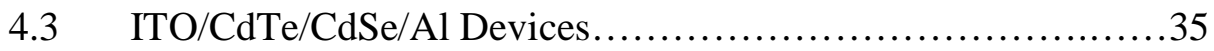

4.3.1 Band Structure ......................................35

4.3.2 Current-Voltage Curves...............................36

4.3.3 Tabulated Results...................................37

4.3.4 Quantum Efficiency..................................38

4.3.5 Discussion............................................. 38

$4.4 \quad$ ITO/ZnTe/CdTe/CdS/Al Devices...............................39

4.4.1 Band Structure........................................39

4.4.2 Current-Voltage Curves............................41

4.4.3 Tabulated Results.................................41

4.4.4 Discussion.........................................42

5. Summary and Conclusion.....................................44

6. $\quad$ References...................................................... 47 


\section{LIST OF TABLES}

Table 3.1 Deposition conditions for ITO/ZnTe/CdSe/Al devices..................25

Table 3.2 Deposition conditions for ITO/CdTe/CdSe/Al devices..................26

Table 3.3 Deposition conditions for the ITO/ZnTe/CdTe/CdS/Al devices...........26

Table 4.1 Device S35 and S36 Performance Characterization......................30

Table 4.2 Device S55 and S71 Performance Characterization....................33

Table 4.3 Device S75 and S79 Performance Characterization.....................37

Table 4.4 Device S82 and S83 Performance Characterization...................41

Table 5.1 Thin Film Semiconductor Device Summary..........................44 


\section{LIST OF FIGURES}

Figure 1.1 Global Solar PV demand forecast by year and country.................

Figure 1.2 Best solar cells research efficiencies by technology...................6

Figure 2.1 Solar Energy Distribution. Intensity vs. Wavelength..................8

Figure 2.2 The p-n Junction under equilibrium conditions. ......................10

Figure 2.3 Heterojunction under equilibrium.................................

Figure 2.4 Heterojunction under steady state conditions........................11

Figure 2.5 The equivalent circuit of a solar cell...............................17

Figure 2.6 Maximum theoretical efficiencies as a function of band gap.............20

Figure 3.1 Schematic of experimental setup. ................................23

Figure 3.2 Photo of the experimental setup..................................23

Figure 3.3 Plot of Intensity vs. Wavelength of the light source....................28

Figure 4.1 Energy diagram for ITO/CdS/CdSe/Al band offsets...................29

Figure 4.2 Current-Voltage Curves for Device S36........................... 30

Figure 4.3 Energy diagram for ITO/ZnTe/CdSe/Al band offsets....................32

Figure 4.4 Current-Voltage Curves for Device S55.........................33

Figure 4.5 Energy diagram for ITO/CdTe/CdSe/Al band offsets....................35

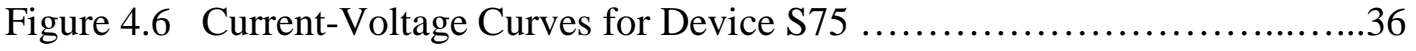

Figure 4.7 Current-Voltage Curves for Device S79. .......................... 37

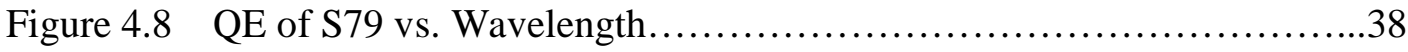

Figure 4.9 Energy diagram for ITO/ZnTe/CdTe/CdS/Al band offsets............40

Figure 4.10 Current-Voltage Curves for Device S83..............................41 


\section{Introduction}

The world depends upon energy for the economic advancement of the developing nations and to sustain the standard of living the industrialized nations have come to expect. According to the International Energy Agency (IEA), the primary energy consumption sources are oil at $34.0 \%$, coal at $26.5 \%$, natural gas at $20.9 \%$, combustible renewables and waste at $9.8 \%$, nuclear at 5.9\%, hydroelectric at $2.2 \%$, and other at $0.7 \%$ [1]. The estimated world wide supply of oil is 42 years, coal 120 years, and natural gas 60 years [2]; it is obvious that alternatives to traditional energy sources must be developed if the world is to meet future energy needs.

\section{$1.1 \quad$ Energy Issues}

Energy issues are the focus of much discussion as the planet has come to realize that the existing paradigms for energy use and production are having long term and lasting effects upon the planet. Limited supplies of traditional energy sources and the increased concentrations of greenhouse gases with resultant global warming are motivating the development and use of renewable energies. The main greenhouse gases are carbon dioxide, nitrous oxide, and methane; the respective concentrations of these gases prior to industrialization were $280 \mathrm{ppm}, 262 \mathrm{ppb}$, and $715 \mathrm{ppb}$, compared to 385 ppm, $322 \mathrm{ppb}$, and $1732 \mathrm{ppb}$ in 2007 [4,5]. Fossil fuel combustion and land use conversion are the main sources of carbon dioxide gas while fossil fuel combustion, rice paddies, landfill waste and livestock account for methane gas with fertilizers, combustions and industrial processes accounting for the production of nitrous oxide. Additionally, fluorinated gases and chlorofluorocarbons and hydro-chlorofluorocarbons 
have been introduced into the atmosphere by industrial sources [5]. All these gases have redistributed in a uniform dispersion around the planet due to long atmospheric lifetimes $[1,4,5]$.

The increase in greenhouse gases has been accompanied by a significant increase in global mean surface temperatures resulting in a reduction of sea ice and a gradual rise in global sea level while the ocean carbon dioxide uptake has increased the average ocean acidity with unknown consequences for ecosystems [4,5].

\subsection{Renewable Energy}

There are two general groupings of renewable energy; there are the combustible renewables such as wood, biogas, biomass, industrial and municipal waste and then there are the renewable energies such as geothermal, solar, wind, and tide/wave/ocean generated to name the most prevalent [1,2]. The focus of this study is photovoltaic (PV) energy, part of the $0.7 \%$ of primary energy consumption sources listed under the aegis of 'other' in the report by the IEA [1]. Of all the renewable resources, solar energy is the most abundant with 162,000 terawatts reaching Earth from the sun, one hour of sunlight could theoretically provide the energy needs of the world for one year [6]. Yet, of the $\sim 1.3 \times 10^{11}$ megawatt hours of energy produced by the world in 2008 , only 13445 megawatt hours were produced from photovoltaic cells, which equates to $\sim 0.00001 \%$ of total primary energy consumption sources $[1,7]$.

\subsection{PV Demand and Cost}

As the price of solar PV continues to become more competitive with traditional energy sources and the world has come to embrace solar energy, the demand for 
photovoltaic modules has increased as shown in Figure 1.1 below $[1,3,6]$. The levelized cost of energy is the ratio of the electricity-generation systems amortized lifetime costs (installed cost plus lifetime operation and maintenance costs) to the system's lifetime electricity generation. The world-wide levelized PV cost runs from $\$ 0.20 / \mathrm{kWh}$ to $\$ 0.80 / \mathrm{kWh}$ with a PV module cost of $\$ 3.65 / \mathrm{Wp}$ (peak Watts) in $2008[3,6]$.

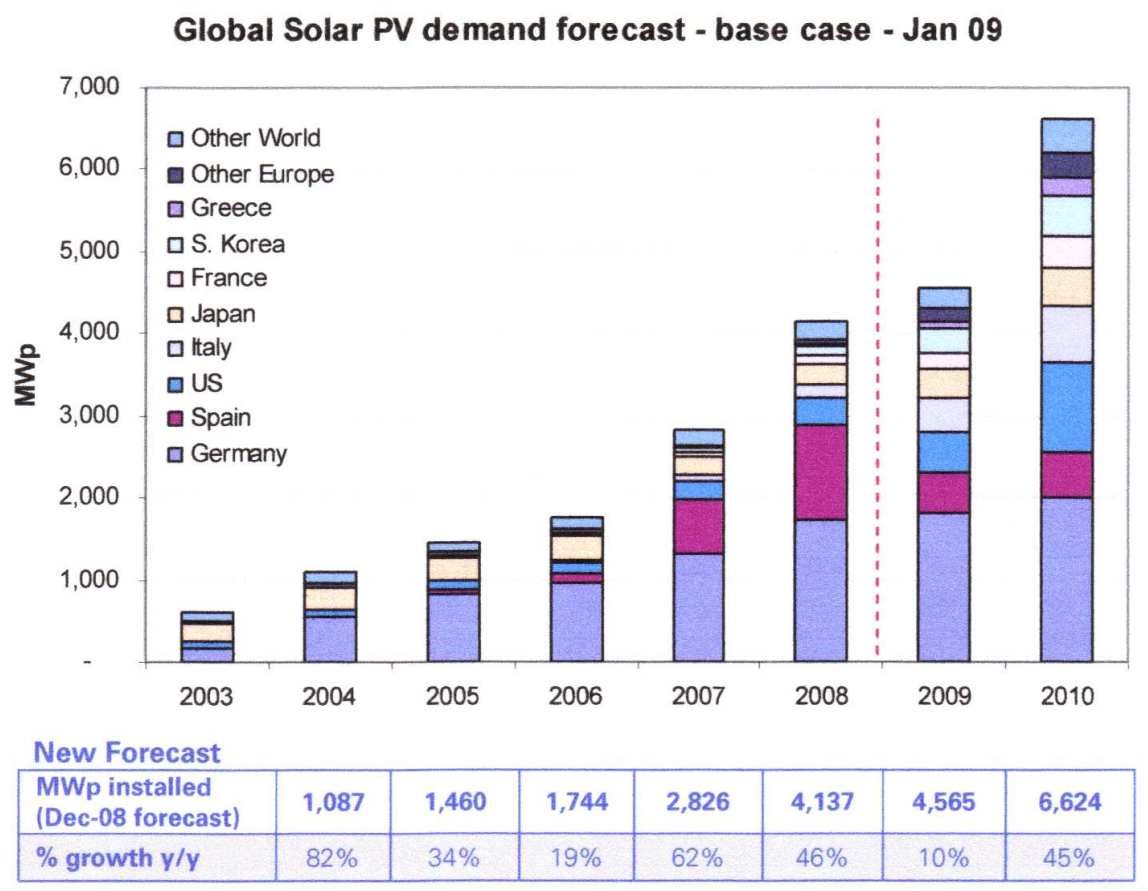

Figure 1.1: Global Solar PV demand forecast by year and country [3].

\section{$1.4 \quad$ Types of Solar Cells}

Two categories of PV cells are used in most of today's commercial PV modules: crystalline silicon and thin films $[1,6,8,9,10]$. The crystalline silicon category, called first-generation PV, includes monocrystalline and multicrystalline PV cells and are the most efficient of the mainstream PV technologies and accounted for $78 \%$ to $84 \%$ of PV modules produced in 2008 [1,3,6,9,11]. Crystalline silicon cells are produced from 
highly refined electronic-grade polysilicon feedstock; the monocrystalline PV cells (c$\mathrm{Si}$ ) are made from single-crystal silicon and multicrystalline PV cells are made from large grain polycrystalline semiconductor films on wafers or other substrates. The single-crystal silicon has higher module efficiencies but the polycrystalline silicon modules are cheaper to manufacture $[1,3,6,12]$.

The thin-film category, called second-generation PV, includes PV cells that produce electricity via extremely thin layers of semiconductor material made of amorphous silicon (a-Si), copper indium diselenide (CIS), copper indium gallium diselenide (CIGS), or cadmium telluride (CdTe). Thin films use less material and generally have lower deposition temperatures. Additionally, thin films have less stringent production parameters and waste thereby making thin films more cost effective than crystalline silicon. The efficiency of thin film has yet to match the efficiency of crystalline silicon but both thin film production and market share, $14 \%$ in 2008 , continues to increase as research and development efforts continue to improve the efficiencies of thin films $[3,6,14,15,16]$. Another second generation PV cell technology is the multijunction PV cell. Multijunction cells use multiple layers of group III-V elements to absorb and convert more of the solar spectrum into electricity than is converted by single-junction cells. Combined with light-concentrating optics and sophisticated sun-tracking systems, these cells have demonstrated the highest sunlightto-electricity conversion efficiencies of any PV technologies.

Various emerging technologies, known as third-generation PV, could become viable commercial options in the future, examples include dye-sensitized and organic 
PV cells that have demonstrated relatively low efficiencies to date, but offer the potential for substantial manufacturing cost reductions. 


\subsection{PV Cell Efficiencies}

The efficiencies of all PV cell types have improved over the past several decades, as illustrated in Figure 1.2, which shows the best research-cell efficiencies from 1975 to 2008 [13]. The highest-efficiency research cell shown is a multijunction concentrator at $40.7 \%$ efficiency. Other research-cell efficiencies illustrated in Figure 1.2 range from $20 \%$ to almost $28 \%$ for crystalline silicon cells, $12 \%$ to almost $20 \%$ for thin film, and about 5\% to $11 \%$ for the emerging PV technologies of organic cells and dye-sensitized cells, respectively.

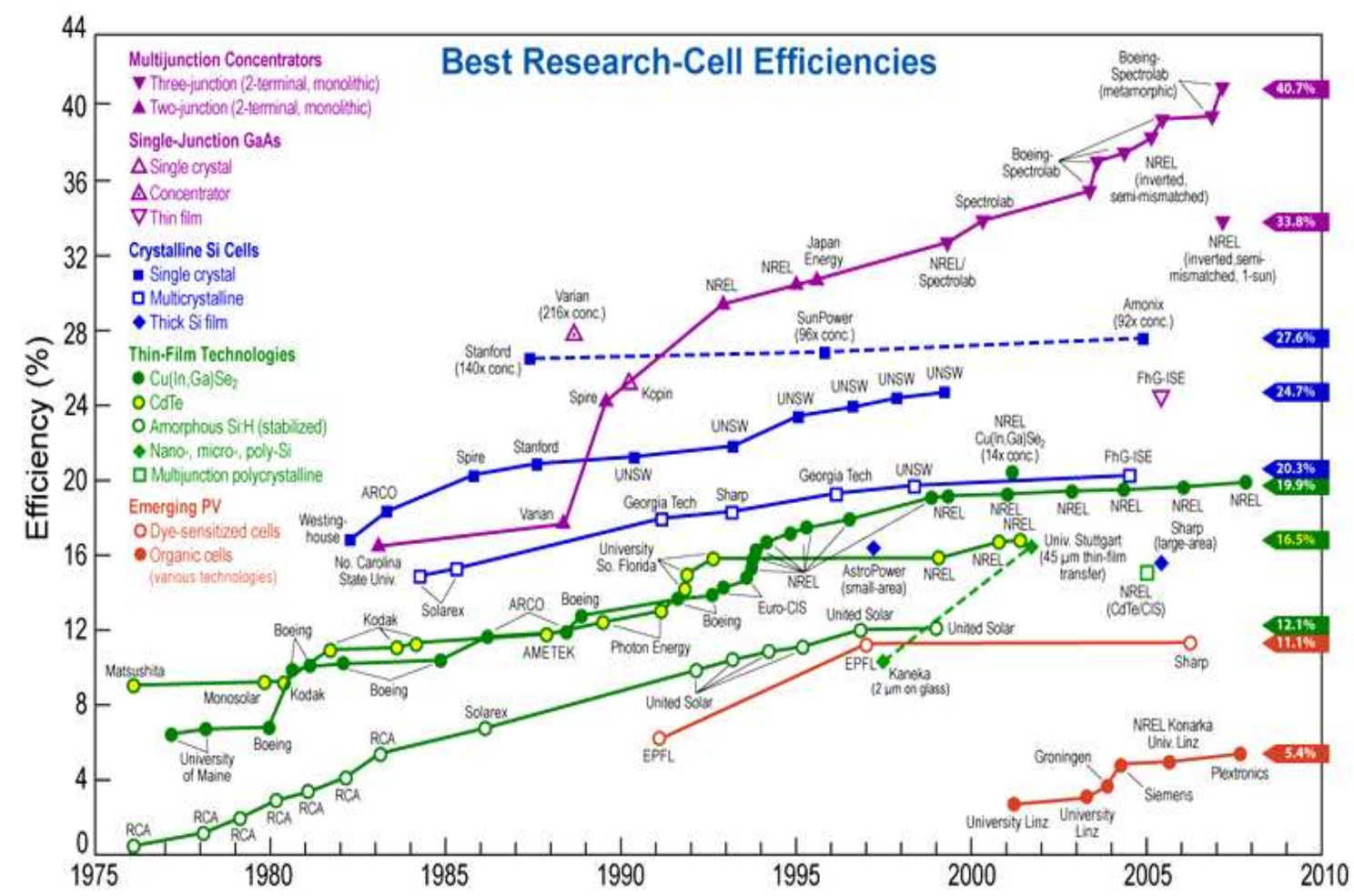

Figure 1.2: Best solar cells research efficiencies by technology [13]. 


\subsection{Focus of Research}

This research studied thin film photovoltaic solar cells composed of un-doped Group II-VI element semiconductor materials, where the compounds were cadmium selenide, cadmium sulfide, cadmium telluride, and zinc telluride. The thin film solar cells made from these semiconductors were heterojunction devices with space charge separation due to energy band offsets as opposed to current production PV modules which have space charge separation enhanced by built in electric fields due to doped $p-n$ junctions $[10,14,15,16,17,18]$. The next section describes the physics and theory that explains the device behavior with emphasis upon device characterization, followed by a section devoted to the experimental apparatus and research techniques. The final chapters present characterization results and discussion of those results followed by the conclusions that can be drawn from this research. 


\section{Principles of Photovoltaic Devices}

\subsection{Solar Spectrum}

Solar cells use photons from the solar spectrum and convert those photons into electricity. The incident photons have various wavelengths $(\lambda)$ and depending upon the wavelength, have an energy that can be expressed in units of electron volts $(\mathrm{eV})$. The amount of energy available from the sun's irradiance has been modeled as having a $5760 \mathrm{~K}$ blackbody spectrum at the top of the atmosphere. The top of the atmosphere has an air mass density equal to zero (AMD0), whereas the surface of Earth has an $\mathrm{AMD}=1.5(\mathrm{AMD} 1.5)$ due to the constituent elements of the atmosphere and the gravitational field. The total energy from the sun's irradiance at the Earth's surface is $932-965 \mathrm{~W} / \mathrm{m}^{2}$, which has been normalized to $1000 \mathrm{~W} / \mathrm{m}^{2}$ for ease of application.

Figure 2.1 illustrates wavelength distribution of the solar spectrum.

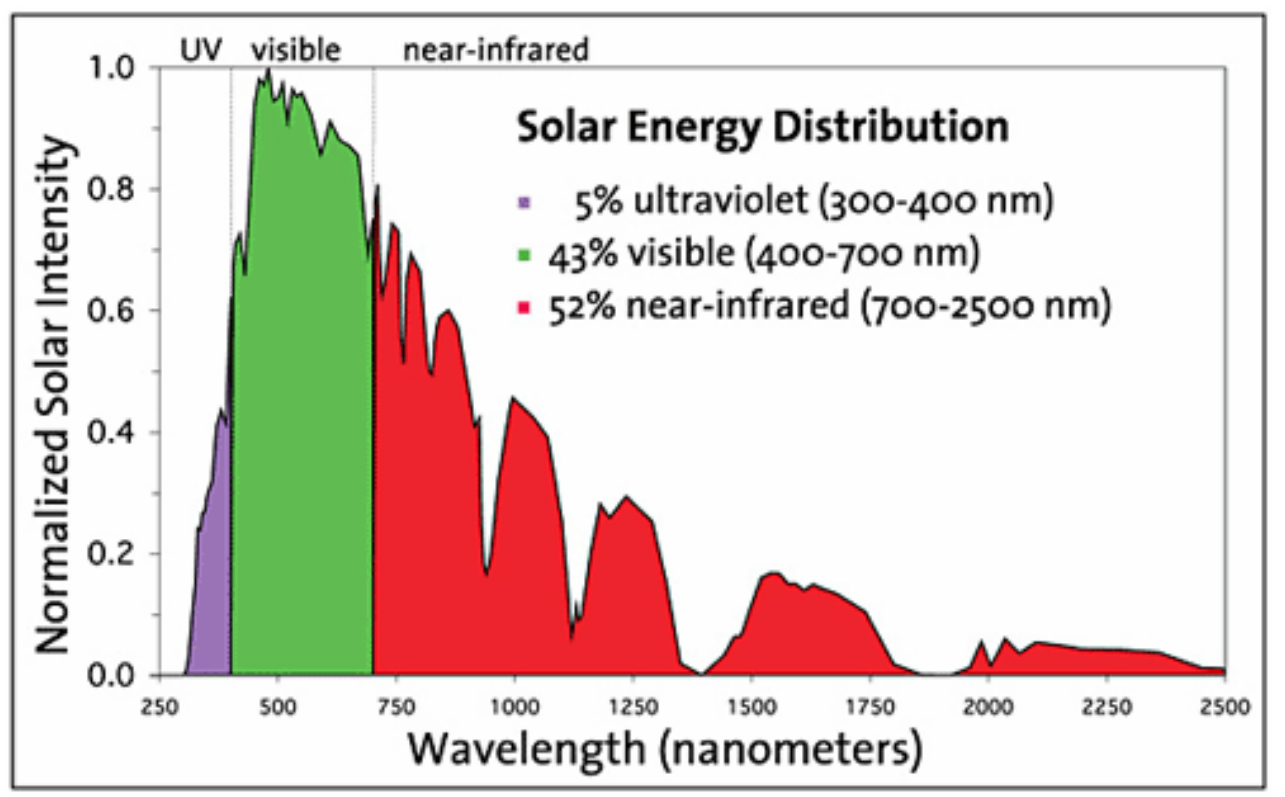

Figure 2.1 Solar Energy Distribution. Intensity vs. Wavelength at AMD1.5 


\subsection{Photovoltaic Solar Cells}

Solar cells convert photons into a photocurrent. The elements that comprise the solar cell determine what wavelengths from the solar spectrum are converted into electricity. A photon may be absorbed by a photovoltaic semiconductor if it has enough energy to create an electron-hole pair in the material provided there are no defects. The minimum energy for absorption depends upon the bandgap $\left(\mathbf{E}_{\mathbf{g}}\right)$ of the material, which is the energy required to excite an electron to the conduction band $\left(\mathbf{E}_{\mathbf{c}}\right)$ and leave a hole in the valence band $\left(\mathbf{E}_{\mathbf{v}}\right): \mathbf{E}_{\mathbf{g}}=\mathbf{E}_{\mathbf{c}}-\mathbf{E}_{\mathbf{v}}$.

Charge separation is often enhanced at the interface between two materials by the presence of intentionally added impurities (doping) which create a built in bias $\left(\mathbf{V}_{\mathbf{b i}}\right)$ at the interface of the semiconductors. The photovoltaic effect in this investigation results from photons incident upon the thin film solar cell, causing photogeneration of electron-hole pairs with electrons promoted into the conduction band (CB) while holes are created in the valence band (VB) through differences in band offsets alone.

\subsubsection{The p-n Junction}

A p-n junction is formed when a layer of $\mathrm{p}$-type semiconductor and a layer of $\mathrm{n}$ type semiconductor are brought into contact with one another. Carriers diffuse across the junction leaving behind a space/layer of fixed charge due to the now ionized atoms on each side of the junction. This space charge sets up an electrostatic field that opposes continued diffusion of carriers across the junction eventually creating equilibrium between the majority and minority carriers. At this equilibrium point, the Fermi level of the p-type and n-type materials are the same due to a built in bias $\left(\mathbf{V}_{\mathbf{b i}}\right)$ which 
compensates for differences in the work functions across the junction. Figure 2.2 illustrates the semiconductor-semiconductor p-n junction.

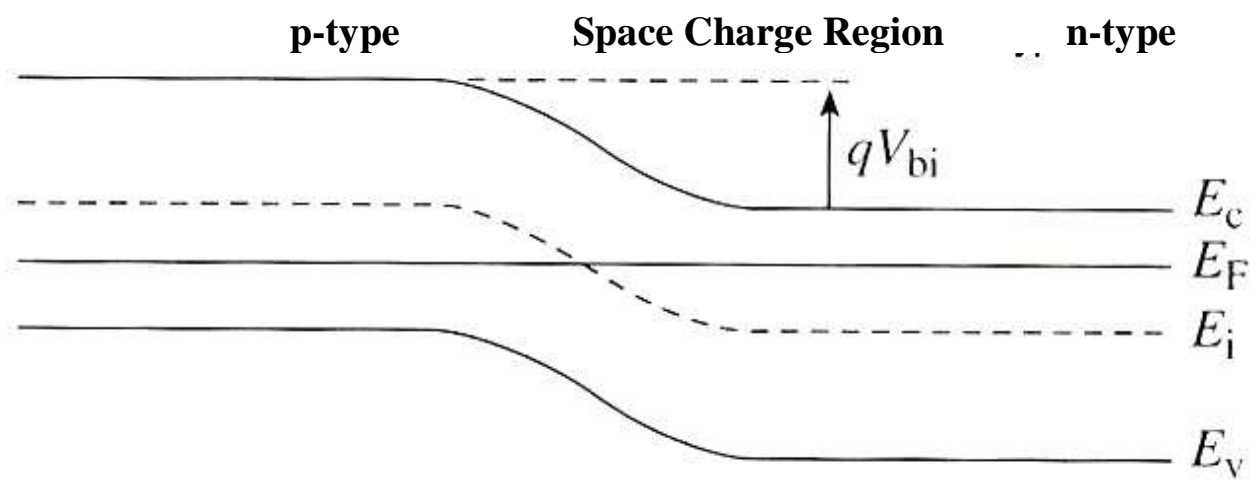

Figure 2.2 The p-n Junction under equilibrium (non illumination) conditions.

2.2.2 The Un-doped Semiconductor-Semiconductor Heterojunction.

In this study, rather than charge separation via the introduction (doping) of donors or acceptors into the appropriate semiconductor material, we have used heterogeneous un-doped semiconductors from Group II-VI compounds relying upon the energy band offsets to provide the necessary intrinsic asymmetries to drive holes and electrons from their points of creation and be transported to their respective electrical contacts. The semiconductor-semiconductor heterojunction has no built in electrostatic field prior to illumination as with the p-n junction. Carrier transport in the un-doped heterojunction is reliant upon the diffusive properties of the semiconductor.

Mechanisms that lead to photogeneration of carriers and their transport are summarized in the following sections. Figures 2.3 and 2.4 illustrate the heterojunctions of this research. 


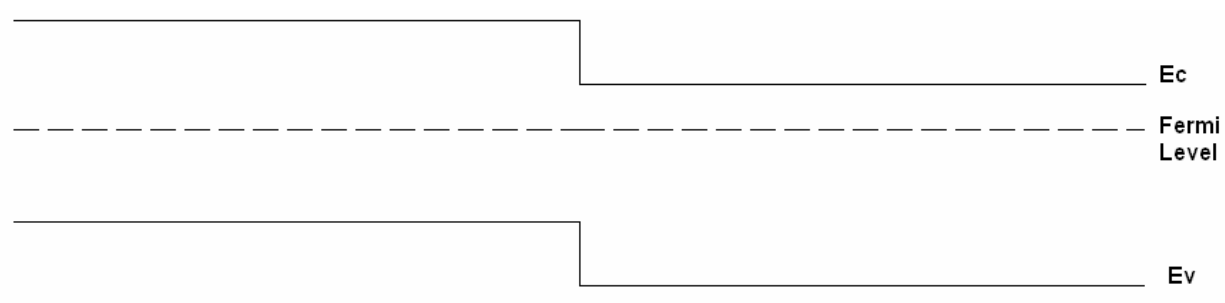

Figure 2.3 Heterojunction under equilibrium (non-illumination). Note that there is no space charge region at the interface of Semiconductor 1 to semiconductor 2.

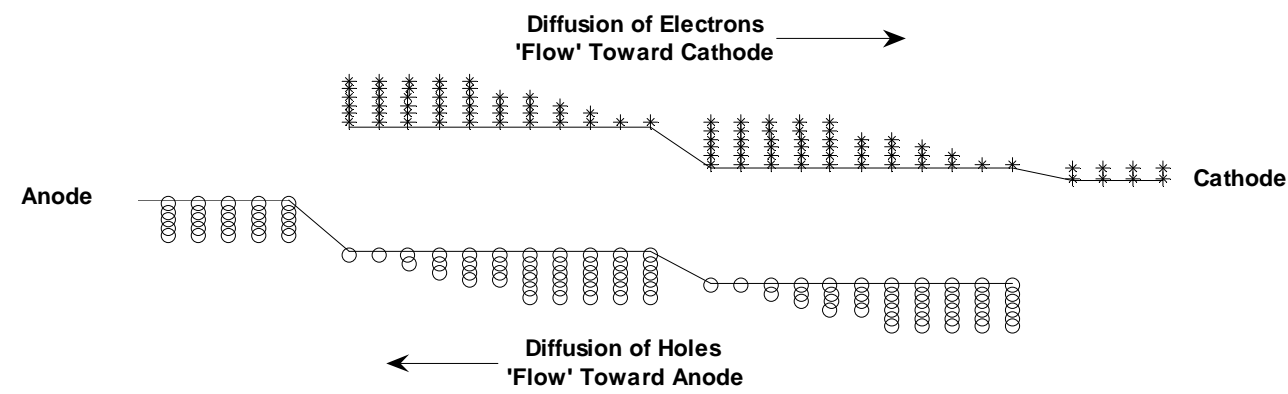

Figure 2.4 Heterojunction under steady state conditions (illuminated).

Note that a space charge region has been established by barriers created by differences in electron/hole densities between semiconductors. Diffusion is toward lower energy states for the electrons and the holes.

\subsection{Photogeneration}

The basis for photogeneration in solar cells is the creation of mobile electrons and holes through the absorption of photons. If photons (with a wavelength $\lambda$ ) are incident upon a semiconductor and are equal to or greater than the band gap energy $\left(\mathbf{E}_{\mathbf{g}}\right)$ 
of the semiconductor, then some of the incident photons will impart their energy to electrons in the valance band and promote those electrons to the conduction band, simultaneously creating holes in the valance band. The rate of spectral photogeneration $(\mathbf{g}(\mathbf{E}, \mathbf{x}))$ is a function of the intensity of the incident photons, the sum of the absorption cross sections for optical processes per unit volume of material and the photon flux $\left(\mathbf{b}_{\mathbf{s}}(\mathbf{E})\right)$ at some depth $\mathrm{x}$. If we assume that all photons of sufficient minimum energy are absorbed and result in carrier generation; then the spectral photogeneration rate with respect to some depth $\mathrm{x}$ is:

$$
g(E, x)=(1-R(E)) \alpha(E) b_{s}(E) e^{-\int_{0}^{\mathbf{x}} \alpha(E, \mathbf{x}) d \mathbf{x}}
$$

The total generation rate is:

$$
G(\mathbf{x})=\int_{E_{g}}^{E_{\max }} g(\mathbf{E}, \mathbf{x}) d \mathbf{E}
$$

Note that the integration is from $\mathbf{E}_{\mathbf{g}}$ to $\mathbf{E}_{\mathbf{m a x}}$ of the incident photon energies $[17,18$,$] .$

It is the number of incident photons with energies above $\mathbf{E}_{\mathbf{g}}$ and not the total energy of the incident photon flux that defines the photogeneration rate. Additionally carrier generation can occur when a photon is absorbed and creates a more excited state which is greater than the exciton binding energy. The exciton is a bound state created by Coulombic interaction between an electron-hole pair with the same wavevector $\mathbf{k}$. Electron-hole pair production via overcoming the excitonic binding energy can be accomplished with photons of energy less than $\mathbf{E}_{\mathbf{g}}$ but again this effect is small in comparison to photogeneration. Photons that do not result in electron-hole pair production can manifest as thermionic or vibrational energy creating phonons that may in fact promote electrons to a more energetic localized state. Additionally, those 
photons that do not result in electron-hole pair production but manifest as thermionic energy and phonons can change some of the characteristic parameters of the semiconductor

\subsection{Recombination}

The loss of mobile electrons or holes can occur as a result of a number of factors, namely: band to band recombination, Auger recombination, band to impurity/trap recombination and surface recombination. In the thin films of this study, the recombination effects that are relevant are the band-to-band, Shockley-Read-Hall, and surface recombination events. These thin films all have direct transition energy gaps, therefore, Auger recombination is not a recombination event that will be considered here.

\subsubsection{Band-to-Band Recombination}

Band to band recombination is the dominant recombination event for semiconductors with direct energy band gaps, which is the result of an electron emitting a photon and moving from the $\mathrm{CB}$ to the VB. In band-to-band recombination, the recombination rate $(\mathbf{U})$ is proportional to the density of states for both the electrons (n) and the holes (p) and can be expressed as:

$$
\mathrm{U}=\mathrm{Bnp}
$$

where $\mathrm{B}$ is a proportionality factor that is material specific $[17,18]$.

\subsubsection{Impurity Trap Recombination}

Shockley-Read-Hall recombination is due to defects or mismatches within the crystal lattice that can create trap states that are spatially localized and energetically 
exist between the VB and CB $[17,18,19]$. The mobile free carriers can be captured and bound to the traps. It can also be the case where a hole or an electron in the trap can recombine with a free electron or hole respectively, then the trap is considered a recombination center. The Shockley-Read-Hall recombination rate through a single trap state is:

$$
\mathrm{U}_{\mathrm{SRH}}=\frac{\mathrm{np}-\mathbf{n}_{\mathrm{i}}{ }^{2}}{\tau_{\mathrm{n}, \mathrm{SRH}}\left(\mathbf{p}+\mathbf{p}_{\mathrm{t}}\right)+\tau_{\mathrm{p}, \mathrm{SRH}}\left(\mathbf{n}+\mathbf{n}_{\mathrm{t}}\right)}
$$

Where $\boldsymbol{\tau}_{\mathbf{n}, \mathbf{S R H}}$ is the electron capture lifetime and $\boldsymbol{\tau}_{\mathbf{p}, \mathbf{S R H}}$ is the hole capture lifetime with $\mathbf{p}_{\mathbf{t}}$ and $\mathbf{n}_{\mathbf{t}}$ as the respective hole and electron densities when the Fermi level is equal to the energy of the trap state $[18,19]$.

\subsubsection{Surface Recombination}

Surface recombination events are due to defects that exist at semiconductor surfaces and interfaces. These defects create spatially localized states in the energy bands and are due to broken bonds, extrinsic impurities from the environment or as a result of the semiconductor growth/deposition process. The recombination flux, because it is function of surface interface area rather than a function of volume, can be defined in a manner similar to the Shockley-Read-Hall expression $[17,18]$. That is:

$$
U_{s} \delta x=\frac{n_{s} p_{s}-n_{i}^{2}}{\frac{1}{s_{n}}\left(p_{s}+p_{t}\right)+\frac{1}{s_{p}}\left(n_{s}+n_{t}\right)}
$$

With $\mathbf{p}_{\mathbf{s}}$ and $\mathbf{n}_{\mathbf{s}}$ as the hole density and the electron density at the surface and with $\mathbf{s}_{\mathbf{n}}$ and $\mathbf{s}_{\mathbf{p}}$ as the surface recombination velocity for electrons and the surface recombination velocity for holes respectively. 


\subsection{Drift and Diffusivity}

Drift and diffusivity occur when non-equilibrium conditions for holes and electrons exist under steady state $[18,19]$. To establish a drift current, there must be a net electric field due to the existence of an electrostatic field from a built in bias or an effective electric field due to gradients in the electron affinity and/or gradients in the band gap and/or gradients in the effective band density of states. Diffusion is the result of a current density gradient due to asymmetry in electron and hole mobility. For this steady state (which in this case illumination) quasi Fermi levels for both holes $\left(\mathbf{F}_{\mathbf{p}}\right)$ and for electrons $\left(\mathbf{F}_{\mathbf{n}}\right)$ are created. These quasi Fermi levels allow for the redefinition of the carrier concentrations.

Thus:

$$
p=n_{i} e^{-\left(\frac{E_{i}-F_{p}}{k_{B} T}\right)}
$$

For holes and:

$$
\mathbf{n}=\mathbf{n}_{\mathbf{i}} e^{-\left(\frac{F_{n}-E_{i}}{k_{B} T}\right)}
$$

For the electrons.

The equation of state for the current density for holes $\left(\mathbf{J}_{\mathbf{P}}\right)$ as a function of carrier action can then be written as:

$$
J_{p}=q \mu_{p} p \xi-q D_{p} \nabla p
$$

Where $\boldsymbol{\xi}$ is the electric field and $\mathbf{q}$ is the magnitude of the electron charge and $\boldsymbol{\mu}_{\mathbf{p}}$ is the hole mobility and using the Einstein relationship for the diffusion constant for holes:

$$
D_{p}=q \mu_{p} / k_{B} T
$$


Now:

$$
\nabla \mathbf{p}=\left(n_{i} / k_{B} T\right) e^{\left(\frac{E_{i}-F_{p}}{k_{B} T}\right)}\left(\nabla E_{i}-\nabla F_{p}\right)
$$

Using the identity that:

$$
\xi=\frac{\nabla E_{i}}{q}
$$

Then (2.10) becomes:

$$
\nabla \mathbf{p}=\left(\frac{q p}{k_{B} T}\right) \xi-\left(\frac{p}{k_{B} T}\right) \nabla F_{p}
$$

Substituting (2.12) into (2.8) yields:

$$
J_{p}=q\left(\mu_{p}-\frac{q D_{p}}{k_{B} T}\right) p \xi+\left(\frac{q D_{p}}{k_{B} T}\right) p \nabla F_{p}
$$

Solving the Einstein relationship for $\boldsymbol{\mu}_{\mathbf{p}}$ and substituting into (2.13) becomes:

$$
\mathrm{J}_{\mathrm{p}}=\mu_{\mathrm{p}} \mathbf{P} \nabla \mathbf{F}_{\mathrm{p}}
$$

Applying this same reasoning to electrons yields:

$$
J_{\mathrm{n}}=\mu_{\mathrm{n}} \mathbf{n} \nabla \mathbf{F}_{\mathrm{n}}
$$

This current density is thus a function of electron or hole mobility and the gradient in quasi Fermi levels established under steady state conditions. Electron or hole mobility is a function of the diffusion constant via the Einstein diffusion relationship equations and the quasi Fermi level is a function of both externally and internally created electric fields. The internal electric field is generated by differences in electron and hole mobility; photogeneration and recombination effects, especially the differences in carrier lifetimes; and differences in band gap energies from one material to the other 
[19]. In this research, the lack of doping and the lack of a built in bias imply that the current density is a function of diffusivity.

\subsection{Device Characterization}

\subsubsection{Equivalent Circuit}

The photovoltaic solar cell can be considered as a two terminal device which conducts like a diode in the dark, and through photogeneration generates a photocurrent and an associated photovoltage under illumination. The asymmetry of the band offsets acts as a diode and provides the photovoltage. Figure 2.5 illustrates the equivalent circuit for a solar cell.

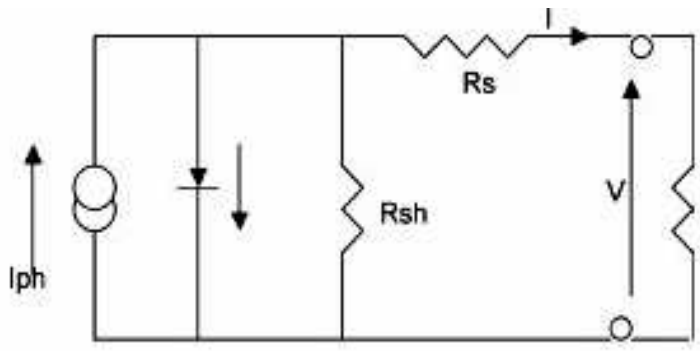

Figure 2.5 The equivalent circuit of a solar cell. $I_{p h}$ is the photon generated current, $R_{s}$ is series resistance, $R_{s h}$ is shunt resistance, $V$ is the voltage across the load resistance-(output).

\subsubsection{Current-Voltage Characteristics}

A solar cell acts as an imperfect diode under an applied bias in the dark. The current density is calculated by adding the short circuit current and dark current, which yields:

$$
J(V)=J_{s c}-J_{\text {dark }}(V)=J_{s c}-J_{0}\left(e^{\left(\frac{q V}{m k_{B} T}\right)}-1\right)
$$


This is the non-ideal diode equation. $\mathbf{J}_{\mathbf{s c}}$ is the short circuit current density, $\mathbf{J}_{\mathbf{0}}$ is a constant, $\mathbf{m}$ is ideality factor and $\mathbf{k}_{\mathbf{B}}$ is the Boltzmann constant $[18,20]$.

\subsubsection{Parasitic Resistances}

Photovoltaic solar cells experience power loss through a series resistance and a shunt resistance. The series resistance results from resistance of the mean current path of the collected carrier to the external load due to front and back contact resistance, semiconductor interface resistance, and any other materials specific resistance. The series resistance can be calculated by measuring I-V curves at several different light intensities and determining the differences between the various short circuit currents. $\mathbf{J}_{\mathbf{s c}}$ is the current measured with illumination and at zero bias and $\mathbf{V}_{\mathbf{o c}}$ is the open circuit voltage measured with illumination and at zero current [18, 21, 22].

This yields:

$$
\mathbf{R}_{\mathbf{S}}=\frac{\Delta \mathbf{V}_{\mathrm{oc}}}{\Delta \mathbf{J}_{\mathrm{sc}}}
$$

Parallel or shunt resistance is due to leakage of current through the cell, around the edges of the cell, and contacts of different polarity. Shunt resistance is a problem in poorly rectifying devices $[18,20]$. It is measured in the dark with an inverse applied voltage and is expressed as:

$$
R_{\text {sh }}=\frac{V}{I}
$$

The diode equation with parasitic resistances included is: 


$$
J=J_{S C}-J_{0}\left(e^{\frac{q\left(V+J A R_{S}\right)}{k_{B} T}}-1\right)-\frac{V+J A R_{s}}{R_{s h}}
$$

\subsubsection{Efficiency}

The power conversion efficiency $(\boldsymbol{\eta})$ of a solar cell is the ratio of the maximum power output to incident light power $[18,20]$ :

$$
\eta=\frac{\mathbf{P}_{\max }}{\mathbf{P}_{\text {in }}}=\frac{\mathcal{J}_{\max } V_{\max }}{\mathbf{P}_{\text {in }}}
$$

There is a fill factor (FF) that is associated with the I-V curve and is defined as the fraction of maximum power output to the ideal power output determined by the open circuit voltage $\left(\mathbf{V}_{\text {oc }}\right)$ and the short circuit current density $\left(\mathbf{J}_{\text {sc }}\right)$ [29]:

$$
\mathrm{FF}=\frac{\mathrm{P}_{\max }}{\mathrm{V}_{\mathrm{OC}} \mathrm{J}_{\mathrm{sc}}}
$$

So the efficiency can be written as:

$$
\eta=\frac{\mathrm{V}_{\mathrm{oc}} \mathrm{J}_{\mathrm{sc}} \mathrm{FF}}{\mathrm{P}_{\mathrm{in}}}
$$

Incident photon to current efficiency (IPCE) or quantum efficiency is determined by the ratio of photons that generate electrons in the load resistance to incident photons of monochromatic light. IPCE may be determined from the measurement of the incident monochromatic light power density and short circuit current density $[18,20]$. It is calculated as: 


$$
\mathrm{IPCE}=\mathrm{QE}=\mathrm{hC}\left(\frac{\mathrm{J}_{\mathrm{sc}}(\lambda)}{\lambda P_{\text {in }}}\right)=\frac{J_{\mathrm{sc}}}{\mathrm{qP}_{\text {in }}}
$$

Where hc is the Plank constant times the speed of light.

The maximum efficiencies of solar cells are controlled by quantum mechanical and thermodynamic effects and are determined using quantum mechanics and statistical mechanics. Figure 2.6 illustrates the calculated theoretical maximum efficiencies of various semiconductors.

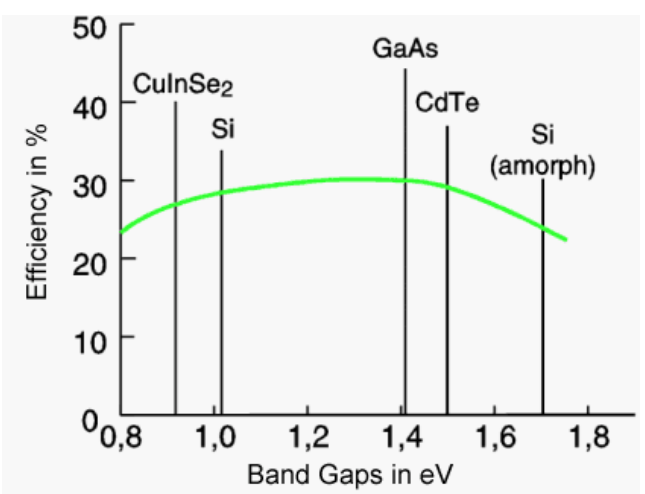

\section{Figure 2.6 Maximum theoretical efficiencies as a function of band gap}

\subsection{Summary}

The physics of the semiconductor PV cell is the physics of the semiconductor. From the previous sections, it is apparent that there are many facets that impact and determine the performance of PV semiconductor devices. Materials specific parameters affect photogeneration and recombination, the introduction of impurities and dopants affect the creation and performance of junctions, resistances affect the current densities and efficiencies, even under optimal conditions with perfect engineering techniques 
there are physical limits on how much power can be converted from the solar spectrum via the semiconductor PV cell. 
3 Experiment: Materials and Methods

\subsection{Materials}

The compounds used in this research were: $99.999 \%$ cadmium selenide (CdSe), 99.999\% cadmium telluride (CdTe), 99.9\% cadmium sulfide (CdS), and 99.998\% zinc telluride (ZnTe). The solar cells were fabricated by evaporating thin semiconductor films onto glass substrates pre-coated with a $100 \mathrm{~nm}$ thick layer of Indium Tin Oxide (ITO) ((222) cubic bixbite) as the front contact. A layer of Aluminum was applied as the back contact. The semiconductor-semiconductor junctions are formed with the following combinations: ITO/ CdS / CdSe /Al; ITO/ CdTe/ CdSe/ Al; ITO/ ZnTe/ CdSe/ Al; ITO/ ZnTe/ CdTe/ CdS/ Al.

\subsection{Experimental Setup for Thin Film Deposition}

The thin films were grown via evaporation in a 2" quartz tube using a Lindberg/Blue M 24” Three-zone $1200{ }^{\circ} \mathrm{C}$ Tube-Furnace(Model 55347-4) controlled by a Lindberg/Blue M Controller. The quartz tube was evacuated using a LeyboldHeraeus Trivac Type D253 Vacuum Pump attached to a Granville-Phillips 275 Convection Gauge. High purity grade Argon was used to purge air from the quartz tube and transport the vaporized compound downstream to the ITO coated glass substrate for deposition. Gas flow was controlled using a mass flow controller made by MKS Instruments Inc. A valve was installed between the flow meter and the quartz tube to reduce initial Argon flow 'burp'. The system layout is shown in Figure 3.1 and in Figure 3.2 below. 


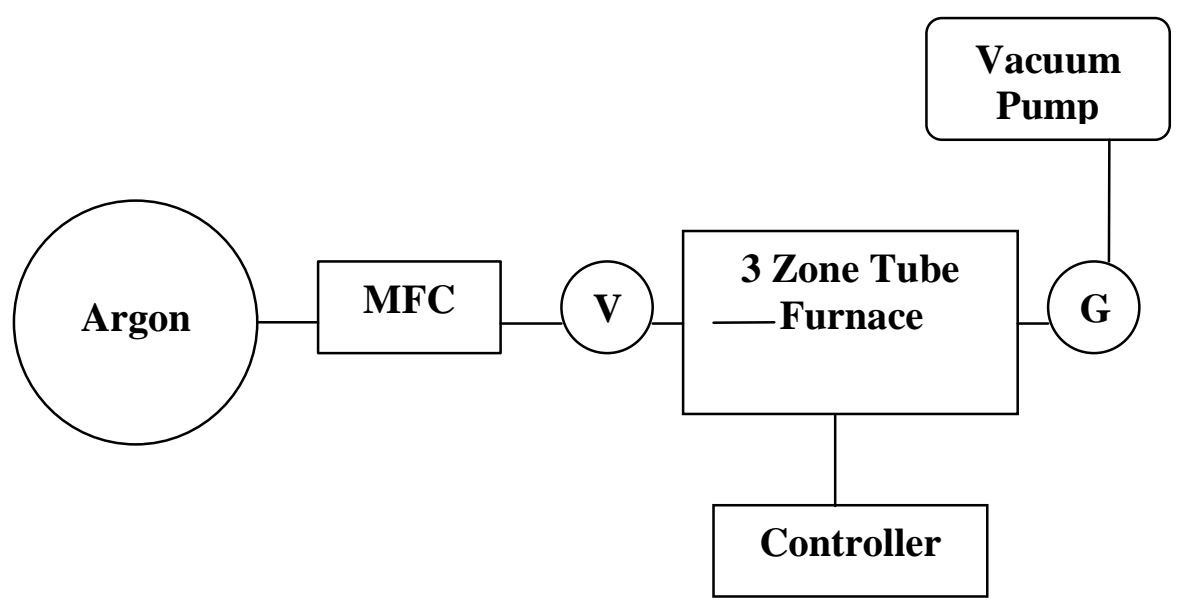

Figure 3.1 Schematic of experimental setup. MFC is mass flow control, $\mathrm{V}$ is valve, $G$ is the convection gauge.

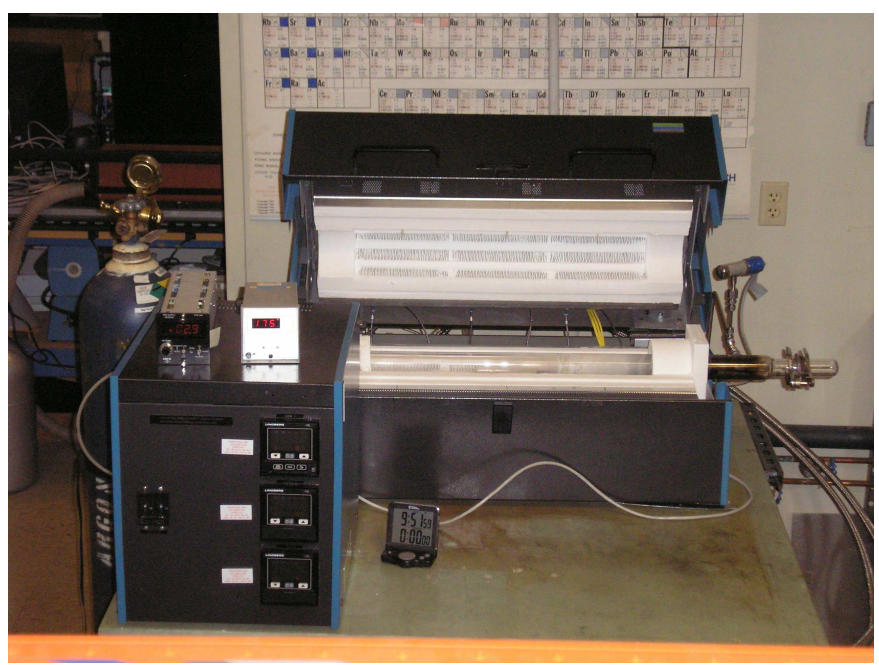

Figure 3.2 Photo of the experimental setup. 
The aluminum thin film back contact was applied at $5 \times 10^{-6}$ Torr using a thin film evaporator with roughing and diffusion pumps.

\subsection{Thin Film Deposition Method}

The Linberg/Blue M Tube Furnace had three 8" independent temperature control zones. Inserting a heat barrier between the second and third zones permitted a heat differential of up to $300{ }^{\circ} \mathrm{C}$ between the first two and the third zone. A quartz boat, which contained the appropriate compound, was placed inside the quartz tube at the center of zone two and the ITO coated glass substrate was placed downstream at the center of zone three. The quartz tube system was then flushed with Argon for 30 minutes and then evacuated by the vacuum pump to a partial pressure of 10-20 mTorr. The quartz tube was then rapidly heated to vaporization and deposition temperatures. When the appropriate temperatures were reached, an Argon gas flow was initiated to provide transport for the deposition process. The Argon gas flow was ceased upon completion of the growth and the quartz tube was again evacuated by vacuum pump and left to cool.

\subsection{Deposition Details}

\subsubsection{ITO/CdS/CdSe/Al Devices}

Cadmium sulfide was deposited upon the ITO substrate via evaporation as described in section 3.3. The quartz boat containing the $\mathrm{CdS}$ was heated to $730{ }^{\circ} \mathrm{C}$ and the substrate heated to $530{ }^{\circ} \mathrm{C}$; deposition occurred for 10 minutes and the entire system cooled to the ambient over a period of several hours. Cadmium selenide was then deposited upon the thin film of CdS via evaporation as described in section 3.3. The 
quartz boat containing the $\mathrm{CdSe}$ was heated to $620^{\circ} \mathrm{C}$ with the substrate temperature of $350{ }^{\circ} \mathrm{C}$. Deposition occurred for 30 minutes and the entire system was then cooled to the ambient over a period of several hours. For the back contact, $200 \mathrm{~nm}$ of aluminum was deposited on the CdSe layer via an evaporator as described in section 3.2.

\subsubsection{ITO/ZnTe/CdSe/Al Devices}

The deposition of Zinc telluride and Cadmium selenide upon the ITO substrate via evaporation as described in section 3.3 occurred similarly to the previous section. The deposition conditions are shown in Table 3.1 below.

\begin{tabular}{|c|c|c|c|c|}
\hline $\begin{array}{c}\text { Device } \\
\#\end{array}$ & II-VI & Temp ${ }^{\circ} \mathbf{C}$ & II-VI & Temp ${ }^{\circ} \mathbf{C}$ \\
\hline S55 & ZnTe & $560 / 300$ & CdSe & $490 / 420$ \\
\hline S71 & ZnTe & $450 / 360$ & CdSe & $350 / 1800$ \\
\hline
\end{tabular}

Table 3.1 Deposition conditions for ITO/ZnTe/CdSe/Al devices.

For the back contact, $200 \mathrm{~nm}$ of aluminum was deposited on the CdSe layer via an evaporator as described in section 3.2.

\subsubsection{ITO/CdTe/CdSe/Al Devices}

Cadmium telluride was deposited upon the ITO substrate via evaporation Then Cadmium selenide was deposited upon the thin film of CdTe via evaporation, both as described in section 3.3. The deposition details are outlined in Table 3.2 below. 


\begin{tabular}{|c|c|c|c|c|}
\hline Device & II-VI & Temp ${ }^{\circ} \mathbf{C}$ & II-VI & Temp ${ }^{\circ} \mathbf{C}$ \\
$\#$ & Compound & / Time (sec) & Compound & / Time (sec) \\
\hline S75 & CdTe & $400 / 45$ & CdSe & $350 / 1800$ \\
\hline S79 & CdTe & $400 / 1200$ & CdSe & $350 / 1800$ \\
\hline
\end{tabular}

Table 3.2 Deposition conditions for ITO/CdTe/CdSe/Al devices.

For the back contact, $200 \mathrm{~nm}$ of aluminum was deposited upon the thin film of CdSe via an evaporator as described in section 3.2.

\subsubsection{ITO/ZnTe/CdTe/CdS/Al Devices}

Zinc telluride was deposited upon the ITO substrate via evaporation and then Cadmium telluride was deposited upon the thin film of ZnTe via evaporation and then Cadmium sulfide was deposited upon the thin film of CdTe via evaporation, all depositions occurred as described in section 3.3. Table 3.3 details the deposition parameters below.

\begin{tabular}{|c|c|c|c|c|c|c|}
\hline Device & II-VI & Temp $^{\circ} \mathbf{C}$ & II-VI & Temp ${ }^{\circ} \mathbf{C}$ & II-VI & Temp ${ }^{\circ} \mathbf{C}$ \\
\hline S82 & Compound & /Time(sec) & Compound & /Time(sec) & Compound & /Time(sec) \\
\hline S83 & ZnTe & $450 / 300$ & CdTe & $400 / 60$ & CdS & $375 / 300$ \\
\hline
\end{tabular}

Table 3.3 Deposition conditions for the ITO/ZnTe/CdTe/CdS/Al devices.

A back contact of $200 \mathrm{~nm}$ aluminum was deposited upon the CdS layer via an evaporator as described in section 3.2. 


\subsubsection{Thickness of the Thin Films}

Semiconductor thin films were deposited upon silicon substrates using the same deposition conditions as the semiconductor thin films in this investigation. The thicknesses of the thin film semiconductors were then determined via ellipsometry.

\subsection{Device Characterization}

\subsubsection{I-V Measurements}

Current-voltage measurements were made using a Keithley 236 Source Measure Unit (SMU). Two wires were connected to each cell with silver epoxy; one was attached to the aluminum back contact and the other to the ITO front contact. The applied bias was swept from $-1 \mathrm{~V}$ to $1 \mathrm{~V}$ at $0.01 \mathrm{~V}$ increments with a compliance value set to $5 \mathrm{~mA}$ and a wait-time of 0.1 seconds with the overall tolerance given as $5 \%$.

Current-voltage measurements were taken for each sample under dark and illuminated conditions; the Keithley $236 \mathrm{SMU}$ was used to measure the $\mathrm{V}_{\mathrm{oc}}, \mathrm{J}_{\mathrm{sc}}, \mathrm{R}_{\mathrm{s}}, \mathrm{FF}$, and $R_{\text {sh }}$ as well as the I-V data as output. Illumination was provided through a $3 / 8$ inch aperture by a 120V 250W ENH Quartzline Lamp with a carbon filter to simulate the solar spectrum. Figure 3.3 is a spectrum of the light source used in this research to imitate the solar spectrum. 


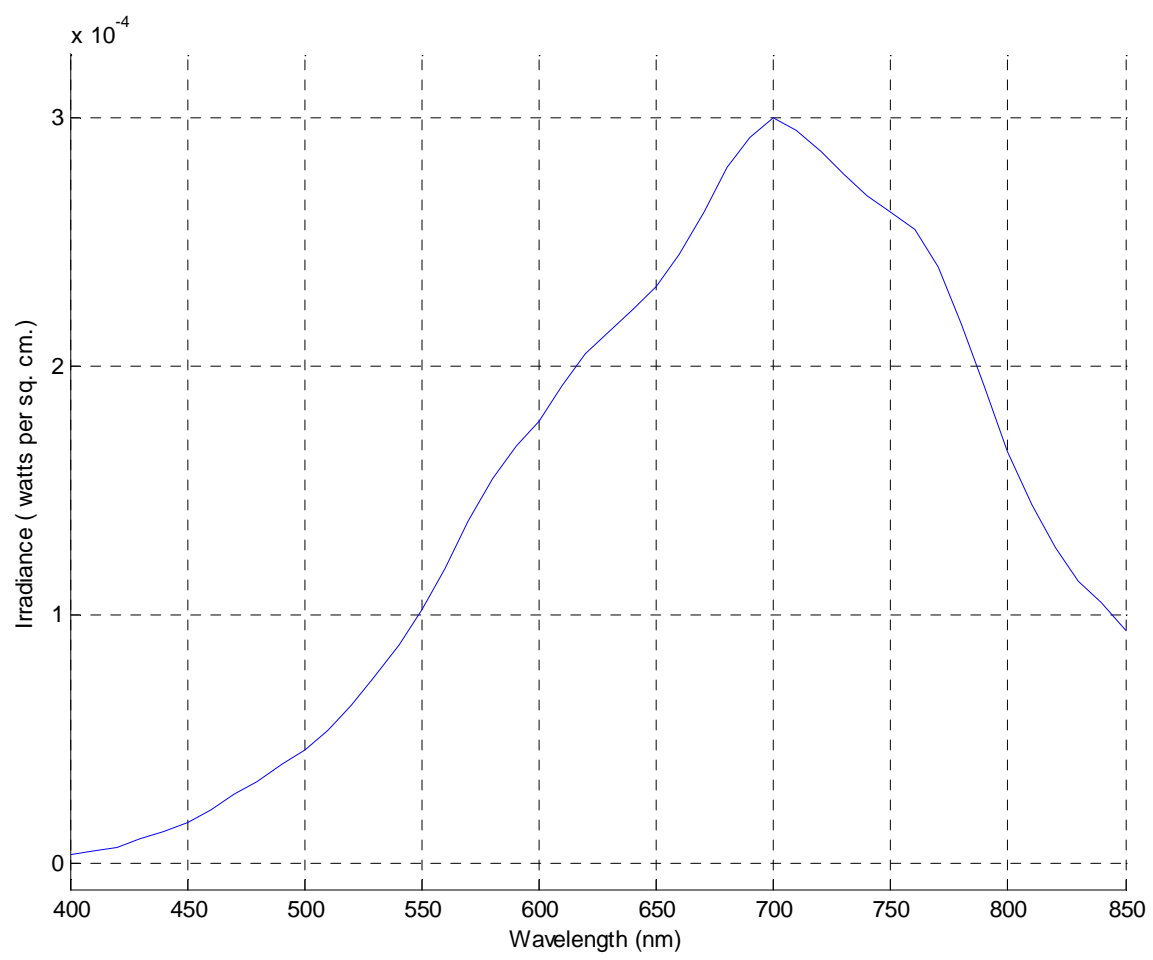

Figure 3.3 Plot of Intensity vs. Wavelength of the light source. This source was used to determine I-V and QE characteristics of devices. There are error bars of \pm $5 \mathrm{~nm}$.

The intensity of the light source was measured at regular intervals to assure consistency in device characterization. There were over eighty devices produced however results of selected devices are presented in the "Results and Discussion" section as representative of the device population. 
4 Results and Discussion

\subsection{ITO/CdS/CdSe/Al Devices}

\subsubsection{Band Structure}

Based on the temperatures used during the deposition processes, both $\mathrm{CdS}$ and Cdse are expected to be hexagonal wurtzite. Cadmium sulfide is a direct band gap semiconductor with an $\mathrm{E}_{\mathrm{g}}$ of $2.48 \mathrm{eV}$, and cadmium selenide is also a direct band gap semiconductor with an $\mathrm{E}_{\mathrm{g}}$ of $1.73 \mathrm{eV}$ [23]. The energy band offset diagram for the $\mathrm{CdS} / \mathrm{CdSe}$ device is illustrated in Figure 4.1 below.

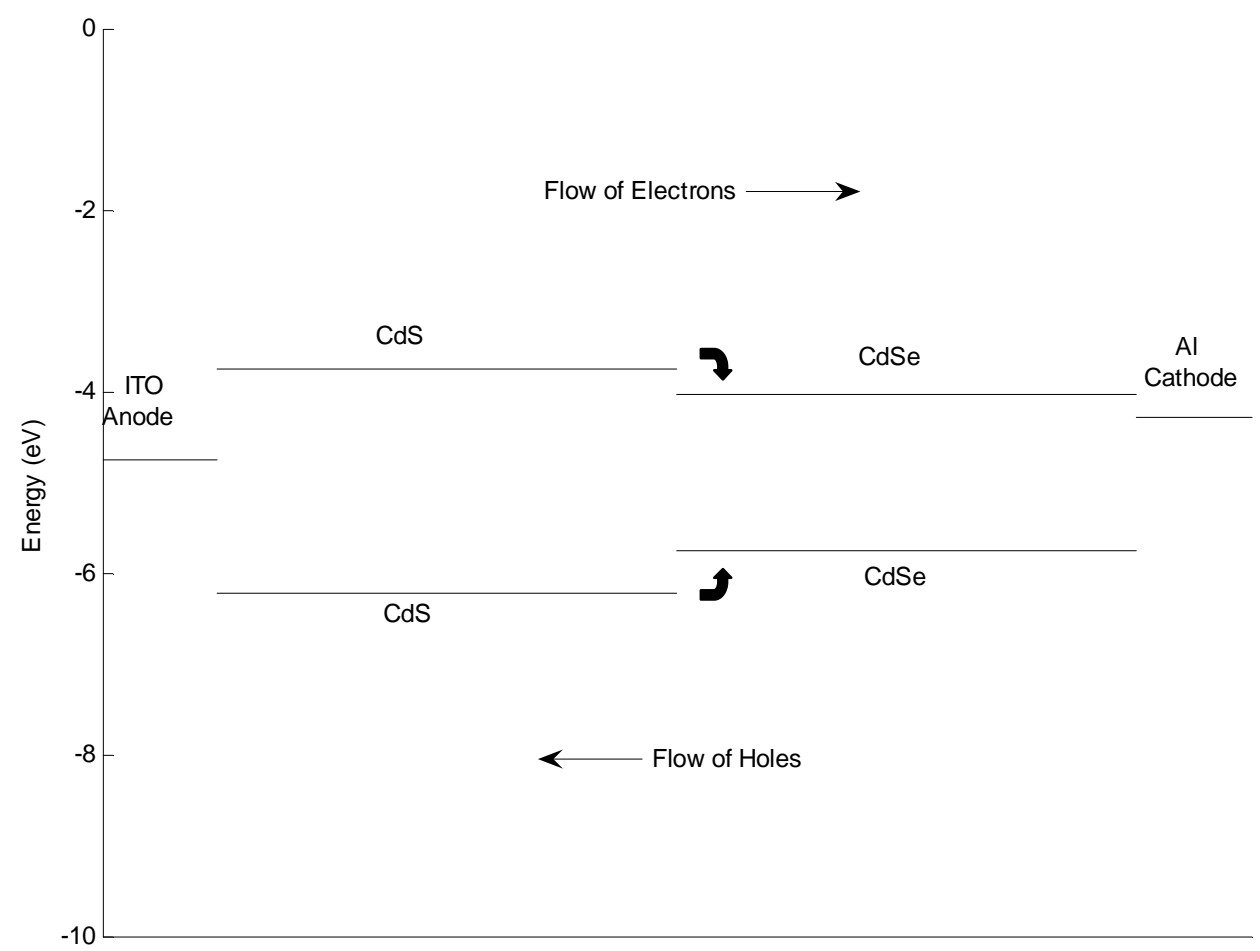

Figure 4.1 Energy diagram for ITO/CdS/CdSe/Al band offsets. Conduction and valence bands are shown. Energy levels are based upon the Fermi-level position where $\mathrm{H}^{+}$and $\mathrm{H}^{-}$have equal formation energy. Zero $\mathrm{eV}$ indicates the vacuum level. The band offsets have error bars of $\pm 0.2 \mathrm{eV}$. Data extrapolated from literature $[23,24]$. 


\subsubsection{Current-Voltage Curves}

Current-voltage curves for a typical device are plotted below in Figure 4.2.

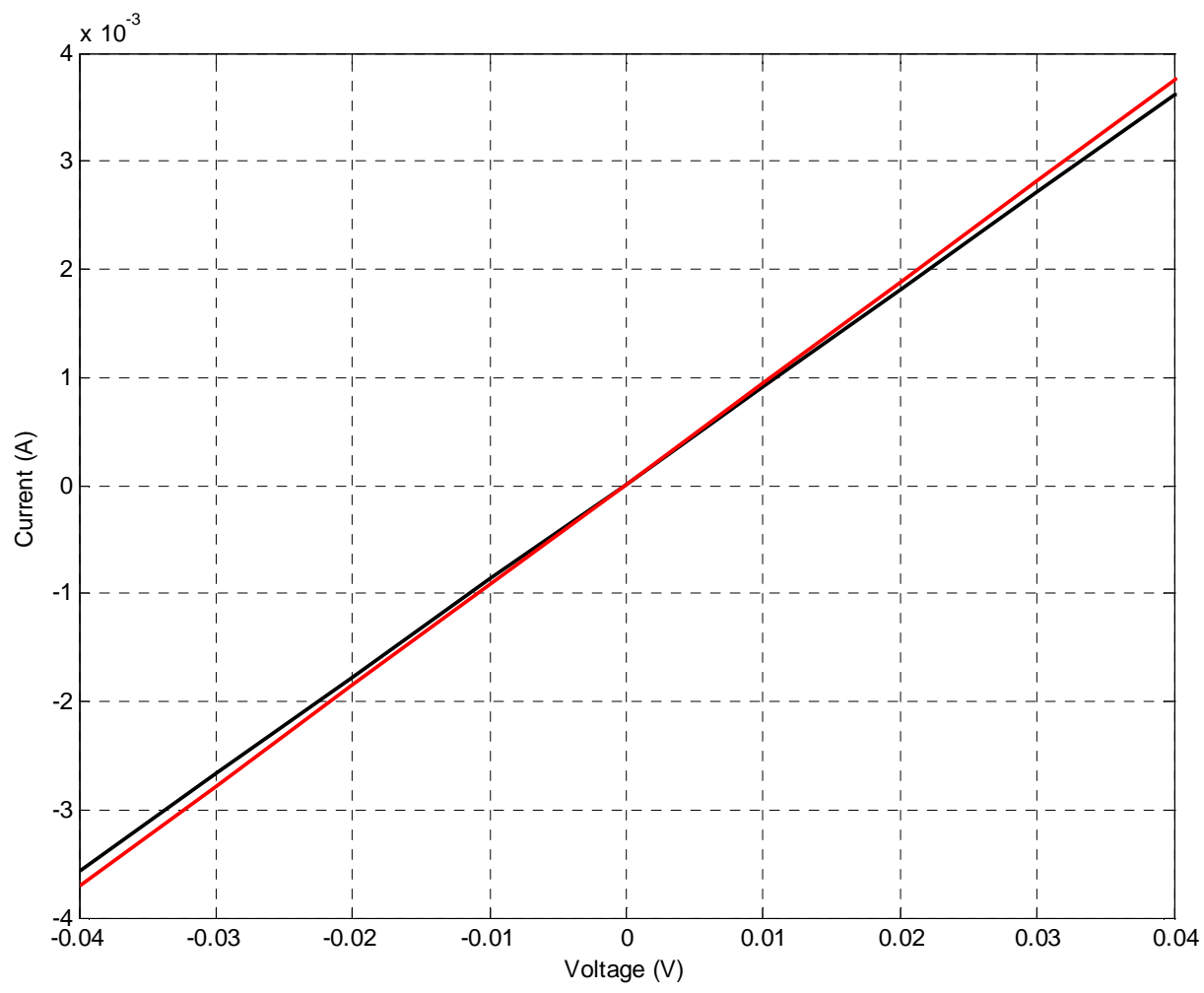

Figure 4.2 Current-Voltage Curves for Device S36. The dark I-V curve is indicated by the black line and the illuminated I-V curve is indicated by the red line. The intensity of illumination was $80.6 \mathrm{~mW} / \mathrm{cm}^{2}$.

\subsubsection{Tabulated Results}

The key measured device parameters for two of these devices are tabulated

below

\begin{tabular}{|l|l|l|l|l|l|l|l|}
\hline Device & $\begin{array}{l}\mathbf{P}_{\text {in }} \\
(\mathbf{m W}) / \mathbf{c m}^{2}\end{array}$ & $\mathbf{V}_{\text {oc }}(\mathbf{V})$ & $\mathbf{J}_{\text {sc }}(\mathbf{m A})$ & $\mathbf{F F} \%$ & $\mathbf{R}_{\mathbf{s}}(\mathbf{\Omega})$ & $\mathbf{R}_{\text {sh }}(\boldsymbol{\Omega})$ & $\boldsymbol{\eta} \%$ \\
\hline S35 & 80.6 & $-2.375 \mathrm{E}-5$ & 0.029 & 0.00 & 8.051 & 8.015 & 0.00 \\
\hline S36 & 80.6 & $-2.905 \mathrm{E}-5$ & 0.0267 & 0.00 & 10.65 & 10.76 & 0.00 \\
\hline
\end{tabular}

Table 4.1 Device S35 and S36 Performance Characterization. 


\subsubsection{Discussion}

The ITO/CdS/CdSe/Al devices were not good photovoltaic solar cells. As can be seen in Figure 4.2, this device acts as a resistor and there were no differences between dark and illuminated conditions. The energy band diagram, Figure 4.1, indicates that separation of electrons and holes are not energetically favorable. Whereas electrons from the CdS CB would be energetically favorable to diffuse toward the cathode, holes in the CdSe VB are not energetically favored to diffuse into the CdS VB as the holes would need to gain energy to do so and would need to 'flow uphill', energetically speaking. As grown, CdS is slightly n-type, so to get this type of device to be a good PV would require the CdSe to be highly n-type doped to move the $\mathrm{CdSe}$ band lower relative to the CdS band creating band-offsets such that electrons would drain into the cathode and holes into the ITO. This would require a lower work function cathode material.

As can be seen in Table 4.1, these devices were $0.0 \%$ efficient and had effectively zero power output. To reiterate the definitions of the parameters in used in Table 4.1 and in those that follow: $\mathrm{P}_{\text {in }}$ is the total power of light incident upon the PV cell, FF is the ratio of the maximum power output to the ideal power output as defined in equation (2.27), the $\mathrm{V}_{\mathrm{oc}}$ is the potential difference when there is zero current present, the $\mathrm{J}_{\mathrm{sc}}$ is the amount of current under illumination with a zero bias, $\eta$ is efficiency based upon the ratio of electrical power output to the power of incident light(section 2.6.4), and $R_{s}$ and $R_{\text {sh }}$ are parasitic resistances as defined in section 2.6.3. However, doped 
$\mathrm{CdS} / \mathrm{CdSe}$ thin film p-n junction devices have yielded a $\mathrm{V}_{\mathrm{oc}}$ of $0.96 \mathrm{~V}$, a $\mathrm{J}_{\mathrm{sc}}$ of $8.6 \mathrm{~mA}$, a FF of $53 \%$, and a $\eta$ of $4.2 \%$, given here for the sake of comparison [30].

\subsection{ITO/ZnTe/CdSe/Al Devices}

\subsection{Band Structure}

Zinc telluride is a direct band gap semiconductor with an $\mathrm{E}_{\mathrm{g}}$ of $2.35 \mathrm{eV}$ whereas cadmium selenide is a direct band gap semiconductor with an $\mathrm{E}_{\mathrm{g}}$ of $1.73 \mathrm{eV}$ [23]. ZnTe is slightly p-type. The energy band offset diagram for the $\mathrm{ZnTe} / \mathrm{CdSe}$ device is illustrated in Figure 4.3 below.

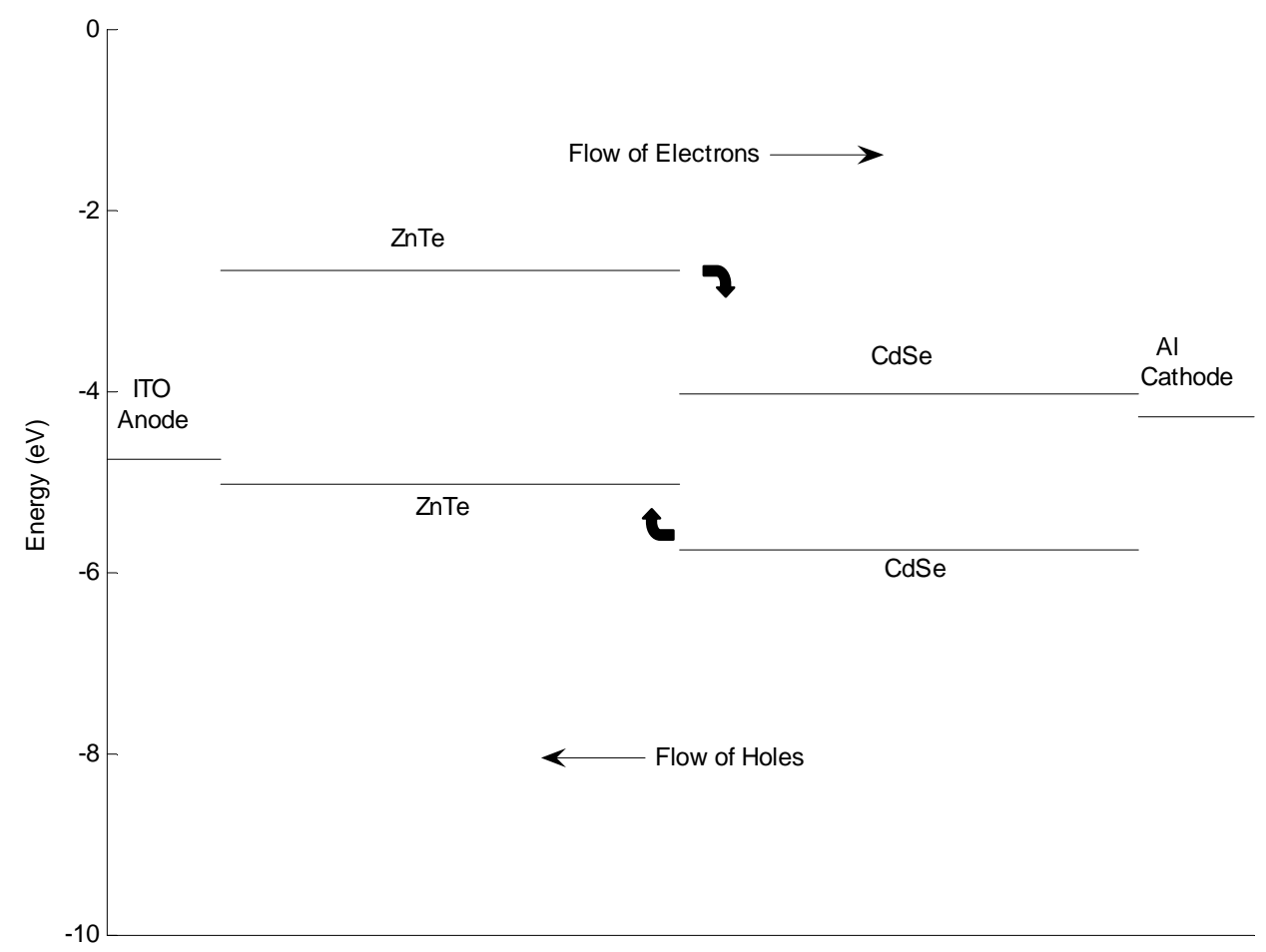

Figure 4.3 Energy diagram for ITO/ZnTe/CdSe/Al band offsets. The band offsets have error bars of $\pm 0.2 \mathrm{eV}$. Data extrapolated from literature $[23,24]$. 


\subsubsection{Current-Voltage Curves}

Current-voltage curves for a typical device are plotted below in Figure 4.4.

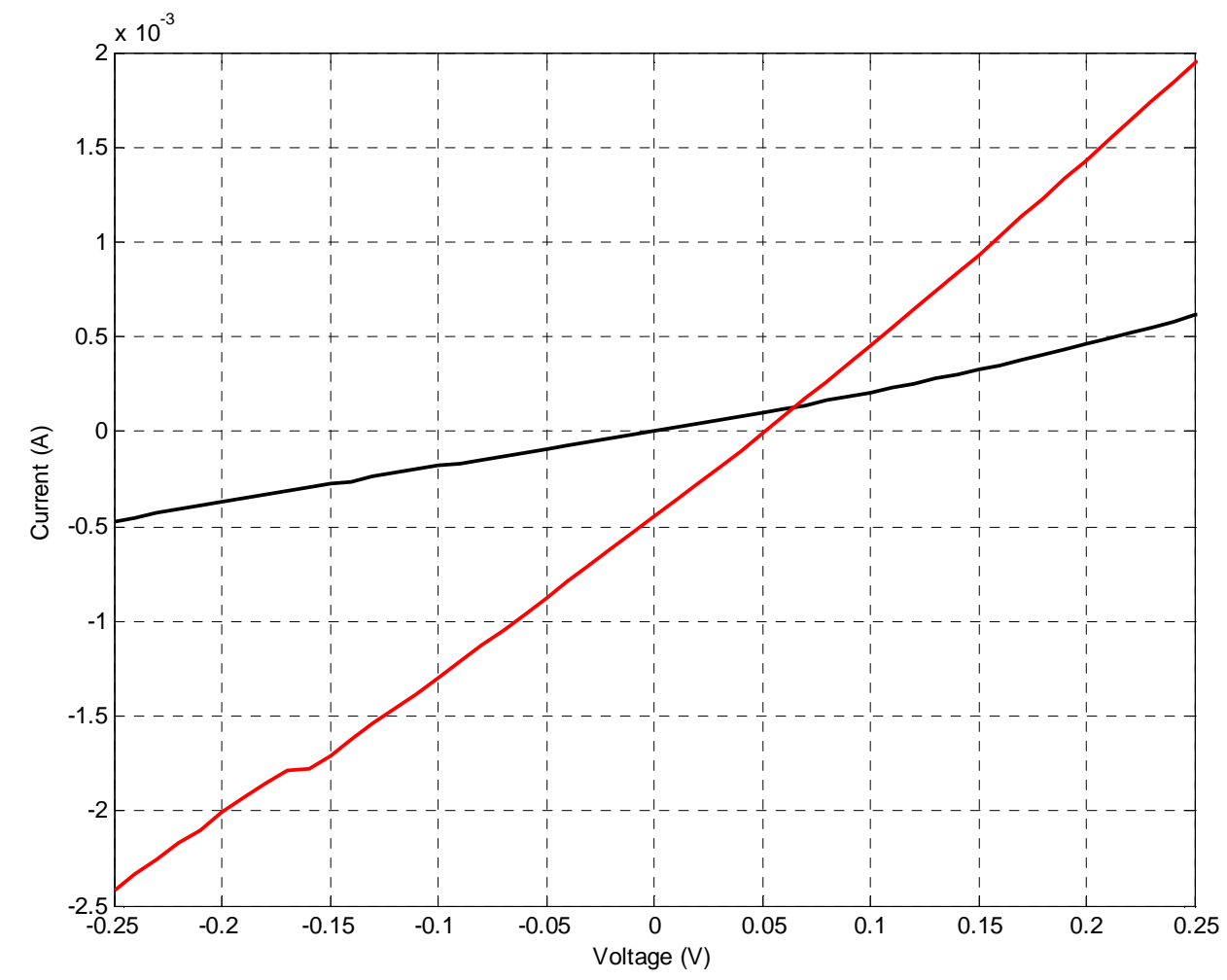

Figure 4.4 Current-Voltage Curves for Device S55. The dark I-V curve is indicated in black and the illuminated I-V curve is indicated in red. The intensity of illumination was $82.0 \mathrm{~mW} / \mathrm{cm}^{2}$.

\subsubsection{Tabulated Results.}

Table 4.2 below provides device parameters for S55 and S71.

\begin{tabular}{|c|c|c|c|c|c|c|c|}
\hline Device & $\begin{array}{c}\mathbf{P}_{\text {in }}(\mathbf{m W}) \\
\mathbf{c m}^{\mathbf{2}}\end{array}$ & $\mathbf{V}_{\text {oc }}(\mathbf{V})$ & $\mathbf{J}_{\text {sc }}(\mathbf{m A})$ & $\mathbf{F F} \%$ & $\mathbf{R}_{\mathbf{s}}(\mathbf{\Omega})$ & $\mathbf{R}_{\text {sh }}(\mathbf{\Omega})$ & $\boldsymbol{\eta} \%$ \\
\hline S55 & 82.0 & 0.05069 & -0.4508 & 25.17 & 95.9 & 555.4 & 0.07 \\
\hline S71 & 80.6 & 0.01905 & -1.39 & 24.31 & 13.52 & 13.64 & 0.079 \\
\hline
\end{tabular}

Table 4.2 Device S55 and S71 Performance Characterization. 


\subsubsection{Discussion}

The energy diagram, Figure 4.3, indicates that electrons should be favored to diffuse from the ZnTe $\mathrm{CB}$ to the $\mathrm{CdSe} \mathrm{CB}$ into the cathode while the holes in the CdSe VB should be energetically favored to 'flow' to the ZnTe VB and into the ITO anode. The differences in the two devices in Table 4.2 are the film thicknesses. Device S55 had a $12 \mathrm{~nm}$ layer of CdSe and a $23 \mathrm{~nm}$ layer of ZnTe. The other (S71) ITO/ZnTe/CdSe/Al devices in this research had thin films that were 4 almost times as thick. The higher shunt resistance may mean that S55 is a poorly rectifying device with electrons flowing from the CdSe CB to the ZnTe VB and toward the anode. This could be the result of Shockley-Read-Hall and surface recombination events due to the position of the ZnTe VB relative to the CdSe conduction band. The energy diagram Figure 4.3 seems to allow this possibility.

As a comparison with doped $\mathrm{ZnTe} / \mathrm{CdSe}$ thin film solar cells, one study reported a $\mathrm{V}_{\mathrm{oc}}$ of $0.450-0.575 \mathrm{~V}$ with a $\mathrm{J}_{\mathrm{sc}}$ of $7-11 \mathrm{~mA} / \mathrm{cm}^{2}$ and a FF of $30 \%$ [31], while another study reported a $\mathrm{V}_{\mathrm{oc}}$ of $0.415 \mathrm{~V}$ with a $\mathrm{J}_{\mathrm{sc}}$ of $11.60 \mathrm{~mA}$ and a $\eta$ of $1.86 \%$ with a FF of $38.6 \%$ [32]. In both of those studies the CdSe was doped n-type with indium while the ZnTe was doped with $\mathrm{Cu}$ in the one case and with $\mathrm{Ag}$ in the other, which would increase the number of electrons in the CdSe CB and increase current flow. 


\subsection{ITO/CdTe/CdSe/Al Devices}

\subsubsection{Band Structure}

Cadmium telluride is a direct band gap semiconductor with an $\mathrm{E}_{\mathrm{g}}$ of $1.48 \mathrm{eV}$; cadmium selenide is a direct band gap semiconductor with an $\mathrm{E}_{\mathrm{g}}$ of $1.73 \mathrm{eV}$ [23]. The energy band offset diagram for the CdTe/CdSe device is illustrated in Figure 4.5 below.

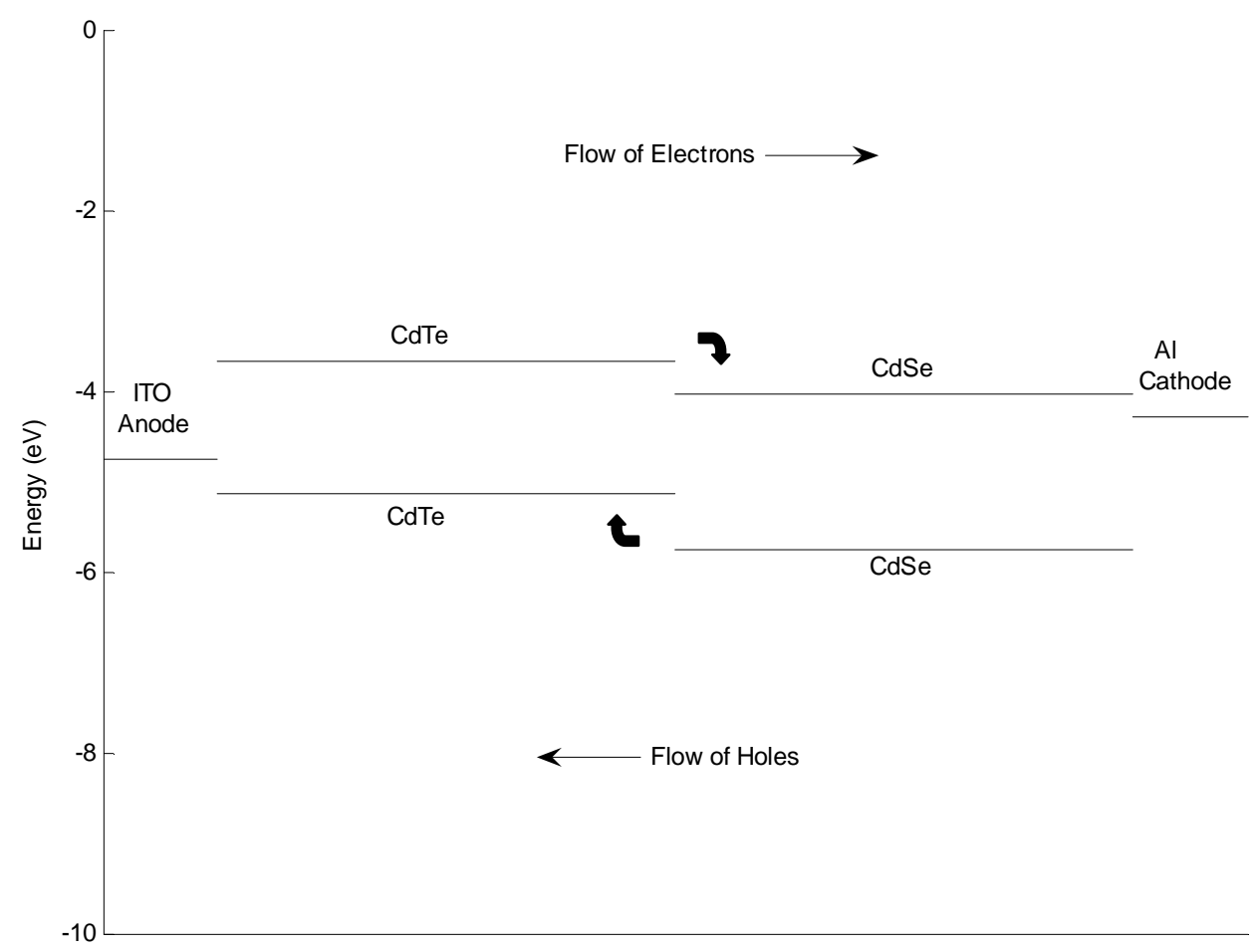

Figure 4.5 Energy diagram for ITO/CdTe/CdSe/Al band offsets. Energy levels are based upon the Fermi-level position where $\mathrm{H}^{+}$and $\mathrm{H}^{-}$have equal formation energy. Zero $\mathrm{eV}$ indicates the vacuum level. The band offsets have error bars of $\pm 0.2 \mathrm{eV}$. Data extrapolated from literature $[23,24]$. 


\subsubsection{Current-Voltage Curves}

Current-voltage curves for devices S75 and S79 are plotted below in Figure 4.6 and Figure 4.7, respectively.

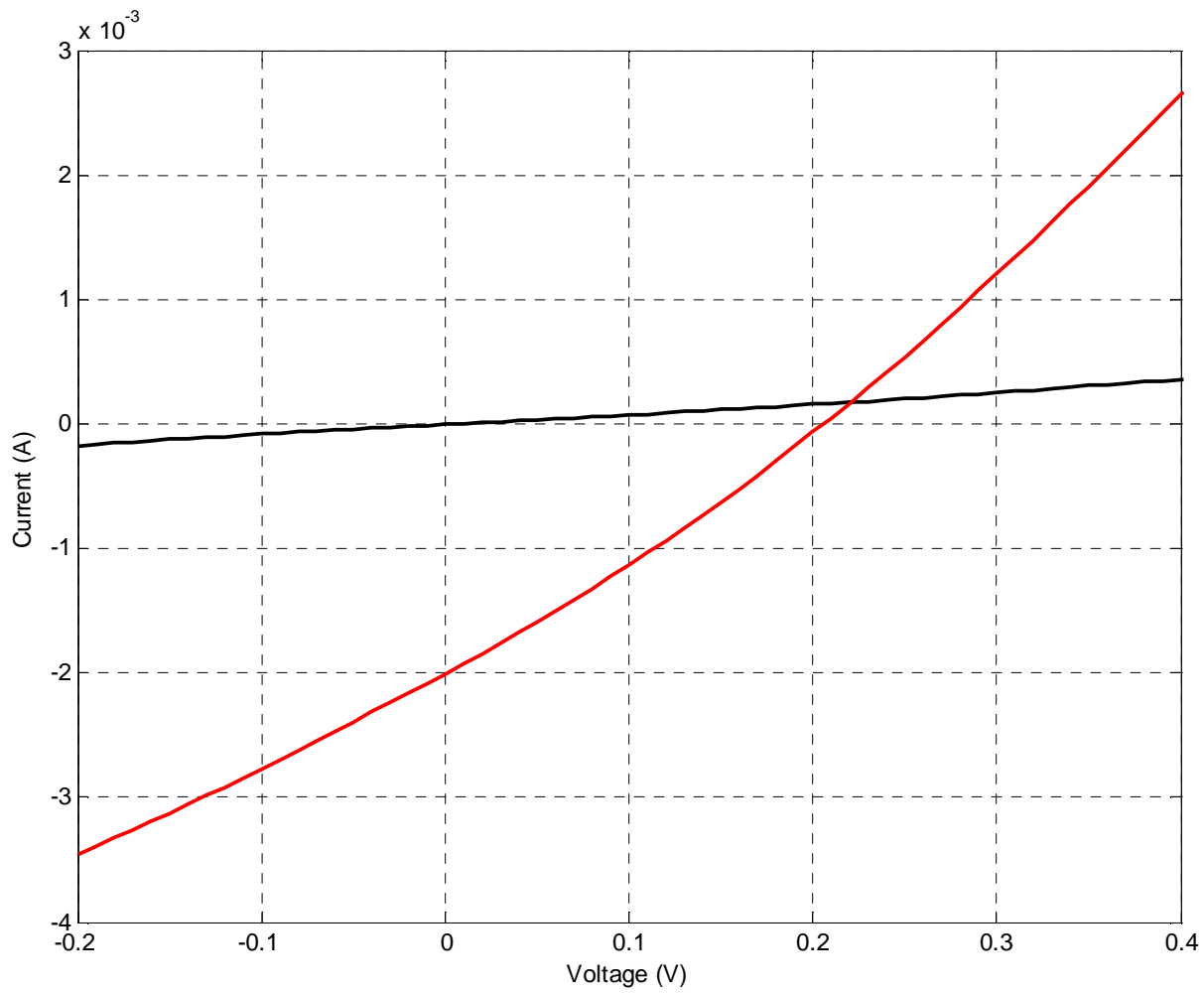

Figure 4.6 Current-Voltage Curves for Device S75. The dark I-V curve is indicated by the black line and the illuminated I-V curve is indicated by the red line. The intensity of illumination was $80.6 \mathrm{~mW} / \mathrm{cm}^{2}$. 


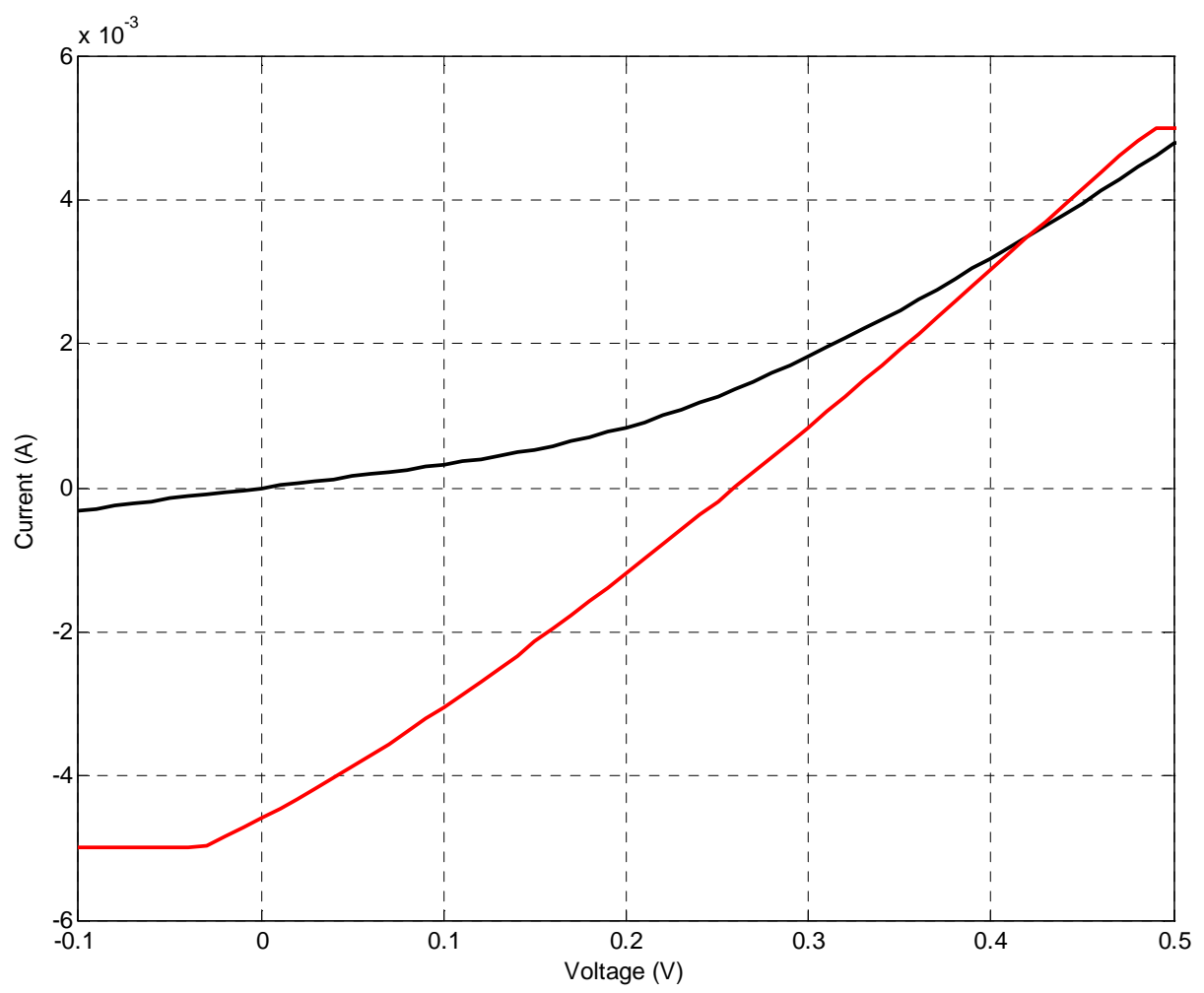

Figure 4.7 Current-Voltage Curves for Device S79. The dark I-V curve is indicated in black and the illuminated I-V curve is indicated in red. The intensity of illumination was $81.4 \mathrm{~mW} / \mathrm{cm}^{2}$.

\subsubsection{Table 4.3 below provides device parameters for S75 and S79.}

\begin{tabular}{|c|c|c|c|c|c|c|c|}
\hline Device & $\begin{array}{c}\mathbf{P}_{\text {in }} \\
\left(\mathbf{m W} / \mathrm{cm}^{2}\right)\end{array}$ & $\mathbf{V}_{\text {oc }}(\mathbf{V})$ & $\mathbf{J}_{\text {sc }}(\mathbf{m A})$ & FF \% & $\mathbf{R}_{\mathrm{s}}(\boldsymbol{\Omega})$ & $\mathbf{R}_{\text {sh }}(\boldsymbol{\Omega})$ & $\eta \%$ \\
\hline S75 & 80.6 & 0.2059 & -2.005 & 27.57 & 63.05 & 153.4 & 0.141 \\
\hline S79 & 81.4 & 0.2592 & -4.59 & 27.47 & 44.56 & 77.13 & 0.401 \\
\hline
\end{tabular}

Table 4.3 Device S75 and S79 Performance Characterization. 


\subsubsection{Quantum Efficiency}

Incident light source intensity measurements allowed for the QE vs. wavelength to be plotted for Device S75 as shown in Figure 4.8.

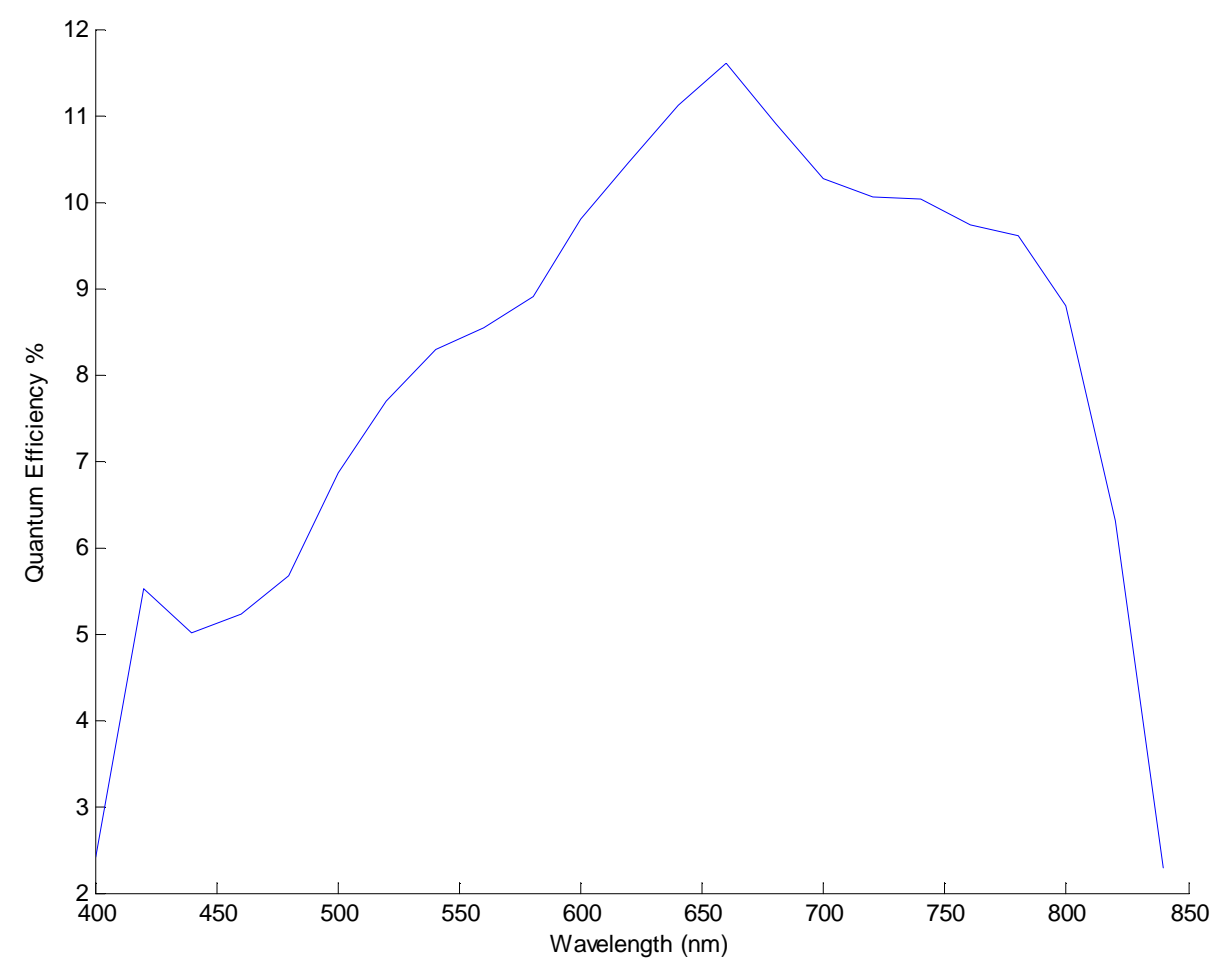

Figure 4.8 QE of S79 vs. Wavelength. There are error bars of $\pm 5 \mathrm{~nm}$.

\subsubsection{Discussion}

The energy band diagram Figure 4.5 indicates that electrons promoted to the

CdTe CB should diffuse favorably to the CdSe CB and to the cathode while holes in the CdSe VB should diffuse toward the CdTe VB and into the anode.

The QE plot closely follows the spectrum of the light source shown in Figure 3.3 , with a maximum efficiency of about $12 \%$. The maximum efficiency varies at about 
$10 \%$ in the $700 \mathrm{~nm}-800 \mathrm{~nm}$ range of the spectrum, well matched to the band-to-band absorption of CdSe and CdTe. Additionally, with the CdTe thin film of device S79 having a thickness of $\sim 174 \mathrm{~nm}$, the absorption of the incident light spectrum should be $<30 \%$ [33] allowing sufficient electron-hole pair production to occur in the CdSe thin film. The spectrum of the incident light source seems to favor the wavelengths with energies greater than the band gap energies of the CdTe and CdSe thin films of these devices.

The only devices in literature to which these $\mathrm{CdTe} / \mathrm{CdSe}$ devices parameters can be compared are $\mathrm{CdTe} / \mathrm{CdSe}$ semiconductor nanocrystal heterostructures (SNCHs) with multiple-branched rod morphology [34]. The SNCH devices were p-type doped with a coating of PEDOT and/or P3HT mixed in with the nanocrystals. The SNCHs had peak absorption at $560-580 \mathrm{~nm}$ with a $\mathrm{V}_{\mathrm{oc}}$ of $0.40 \mathrm{~V}$ and a $\mathrm{J}_{\mathrm{sc}}$ of $0.018 \mathrm{~mA} / \mathrm{cm}^{2}$ with a FF of $38 \%$ and an efficiency $\eta=0.003 \%$ under illumination of AMD1.5 $\left(100 \mathrm{~mW} / \mathrm{cm}^{2}\right)$.

Our ITO/CdTe/CdSe/Al device and the nanorod devices had similar shaped illuminated I-V curves [34]. Our PV cells have absorption wavelengths that respond favorably to the red part of the light spectrum thus making these good PV devices for the solar spectrum (see Figure 2.1). These devices had the best efficiencies of any devices produced in this investigation.

\section{$4.4 \quad \mathrm{ITO} / \mathrm{ZnTe} / \mathrm{CdTe} / \mathrm{CdS} / \mathrm{Al}$ Devices}

\subsubsection{Band Structure}

Zinc telluride is a direct band gap semiconductor with an $\mathrm{E}_{\mathrm{g}}$ of $2.35 \mathrm{eV}$; cadmium telluride is a direct band gap semiconductor with an $\mathrm{E}_{\mathrm{g}}$ of $1.48 \mathrm{eV}$; cadmium 
sulfide is a direct band gap semiconductor with an $\mathrm{E}_{\mathrm{g}}$ of $2.48 \mathrm{eV}$ [23]. Since $\mathrm{ZnTe}$ is slightly p-type and CdS is slightly n-type, this polarity configuration was used to produce a p-i-n junction PV cell. The energy band offset diagram for the ITO/ZnTe/CdTe /CdS/Al device is illustrated in Figure 4.9 below.

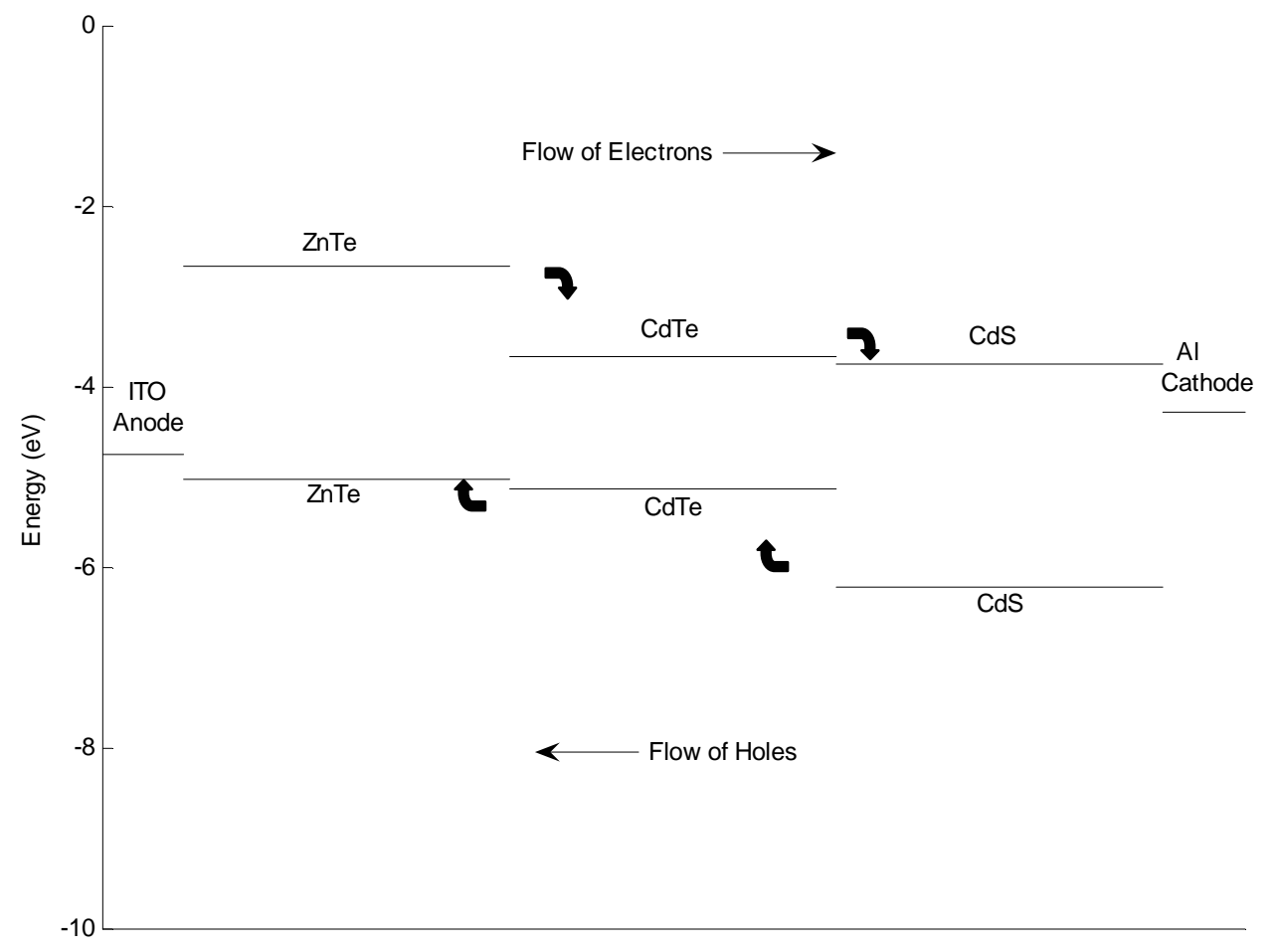

Figure 4.9 Energy diagram for ITO/ZnTe/CdTe/CdS/AI band offsets. Conduction and valence bands are indicated. The band offsets have error bars of $\pm 0.2 \mathrm{eV}$. Data extrapolated from literature [23,24]. 
4.4.2 Current-voltage curves for a typical device are plotted below in Figure 4.10.

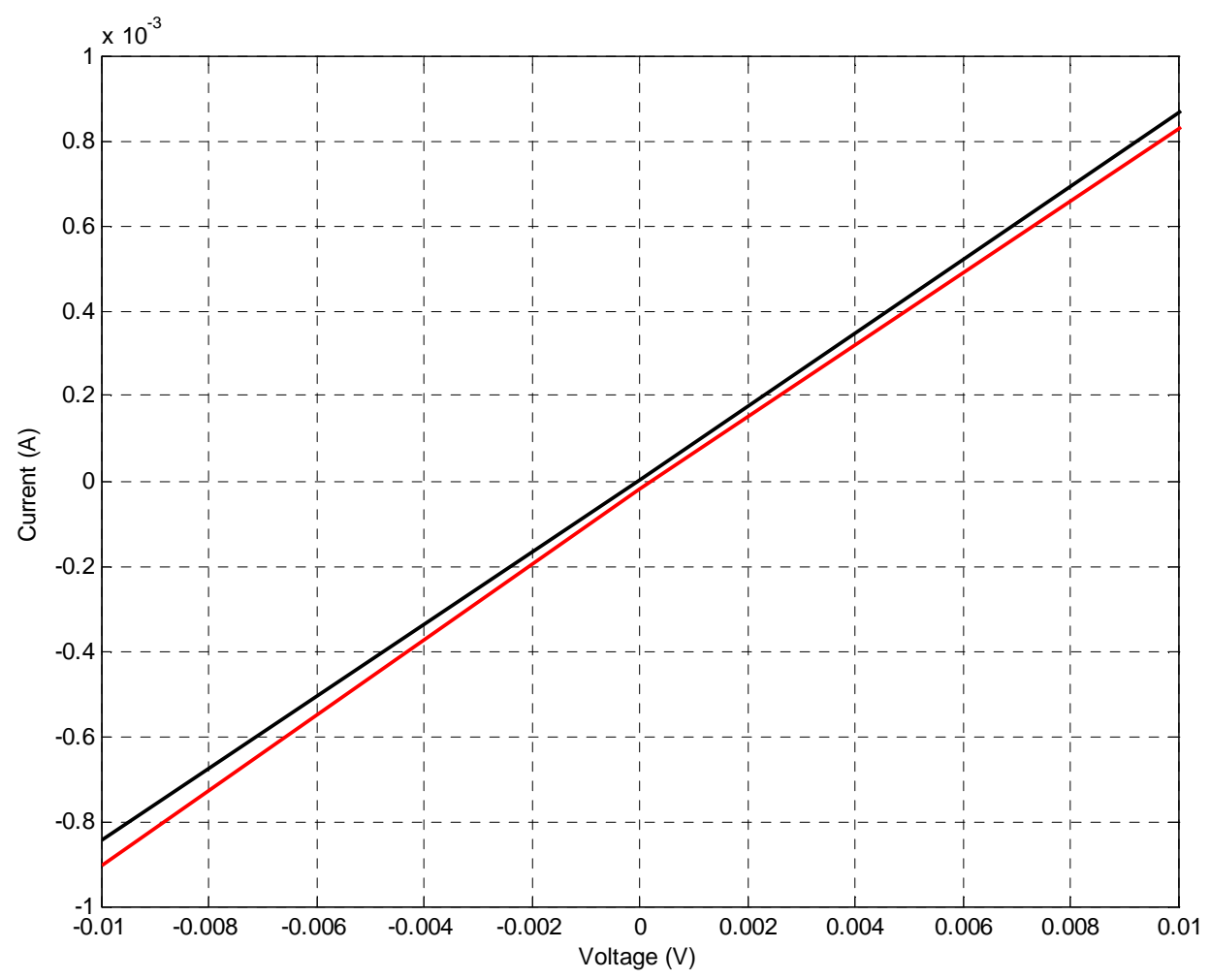

Figure 4.10 Current-Voltage Curves for Device S83. The dark I-V curve is indicated in black and the illuminated I-V curve is indicated in red. The intensity of illumination was $81.4 \mathrm{~mW} / \mathrm{cm}^{2}$.

4.4.3 Table 4.4 below provides device parameters for S82 and S83.

\begin{tabular}{|c|c|c|c|c|c|c|c|}
\hline Device & $\begin{array}{c}\mathbf{P}_{\text {in }} \\
(\mathbf{m W}) / \mathbf{c m}^{\mathbf{2}}\end{array}$ & $\mathbf{V}_{\text {oc }}(\mathbf{V})$ & $\mathbf{J}_{\text {sc }}(\mathbf{m A})$ & $\mathbf{F F}$ & $\mathbf{R}_{\mathbf{s}}(\mathbf{\Omega})$ & $\mathbf{R}_{\text {sh }}(\mathbf{\Omega})$ & $\boldsymbol{\eta} \%$ \\
\hline S82 & 81.4 & $2.132 \mathrm{E}-7$ & $1.924 \mathrm{E}-5$ & 0.00 & 10.96 & 10.58 & 0.0 \\
\hline S83 & 81.4 & $2.483 \mathrm{E}-4$ & $-2.11 \mathrm{E}-5$ & 25.00 & 11.22 & 11.29 & $\sim 0.0$ \\
\hline
\end{tabular}

Table 4.4 Device S82 and S83 Performance Characterization. 


\subsubsection{Discussion}

The energy band offset diagram Figure 4.10 indicates that electron movement from the $\mathrm{ZnTe} \mathrm{CB}$ to the $\mathrm{CdTe} \mathrm{CB}$ is energetically favored, however there is not much energy difference between the CdTe CB and the CdS CB. Similarly, holes are energetically favored to move from the CdS VB to the CdTe VB but there is not much 'fall' between the CdTe VB and the ZnTe VB.

Additionally, ZnTe absorbs photons from the green part $(550 \mathrm{~nm})$ of the light spectra while the CdTe absorbs photons from the red part $(820 \mathrm{~nm})$ of the light spectra. Since CdS absorbs photons from the green part $(500 \mathrm{~nm})$ of the light spectrum it could be expected that there would be a great deal of photogeneration. However there is $\sim 10 \%$ lattice mismatch between Cdte and CdS and therefore Shockley-Read-Hall and surface/interface recombination events are significant [39]. Hence no carriers were produced in the $\mathrm{CdS}$ and as a result the $\mathrm{CdS}$ thin film was highly resistive.

Most of the commercially available CdTe PV modules on the market at this time use a n-i-p junction and are of the form CdS/CdTe/ZnTe [26, 28, 35]. These PV cells are highly doped and produced via chemical vapor depositions (CVD) or closed spaced sublimation CSS) processes using $\mathrm{CdCl}_{2}$ or $\mathrm{HCF}_{2} \mathrm{Cl}$ applied to both $\mathrm{CdTe}$ and $\mathrm{CdS}$ prior to or during the annealing processes $[10,28,35,36,37]$. The thin films commercially produced are considerably thicker, in the range of $\sim 2.5-5.3 \mu \mathrm{m}$ for the CdTe thin film $[6,10,26,36]$, a thickness of $~ 150-300 \mathrm{~nm}$ for the CdS layer[36], and a thickness of $\sim 40-150 \mathrm{~nm}$ fo the $\mathrm{Cu}$ doped $\mathrm{ZnTe}$ [36]. Compared to the PV parameters of our cells in Table 4.4 these doped CdS/CdTe/ZnTe PV cells had the following 
values: $\mathrm{V}_{\mathrm{oc}}$ of $0.0778 \mathrm{~V}$, a $\mathrm{J}_{\mathrm{sc}}$ of $22.4 \mathrm{~mA} / \mathrm{cm}^{2}$, a FF of $74.0 \%$, a $\mathrm{R}_{\mathrm{s}}<10 \Omega$, and a $\mathrm{R}_{\mathrm{sh}}>$ $2000 \Omega[10,35,36]$. 


\section{Summary and Conclusions}

During the course of this investigation, 85 thin film semiconductor PV cells were produced via evaporation using a three-zone tube furnace. The thin films were all un-doped Group II-VI compounds and deposition occurred in combinations that were possible with the apparatus used in this research. Some combinations were attempted but were not possible because the temperature of deposition for the second thin film layer caused the first deposition to evaporate from the substrate before the next thin film could deposit. The depositions used in this research with selected parameters are included in Table 5.1 below.

\begin{tabular}{|c|c|c|c|c|c|}
\hline $\begin{array}{c}\text { Device } \\
\#\end{array}$ & $\begin{array}{c}\text { II-VI } \\
\text { Composition }\end{array}$ & $\begin{array}{l}\text { Thickness } \\
\text { Film nm }\end{array}$ & $\begin{array}{l}\text { Deposition } \\
\text { Temps }^{\circ} \mathrm{C}\end{array}$ & $\begin{array}{l}\text { Depositions } \\
\text { In Seconds }\end{array}$ & $\begin{array}{l}\eta \\
\%\end{array}$ \\
\hline S35 & CdS/CdSe & $62 / 50$ & $530 / 350$ & $600 / 1800$ & $\mathbf{0}$ \\
\hline S36 & CdS/CdSe & $62 / 50$ & $530 / 350$ & $600 / 1800$ & $\mathbf{0}$ \\
\hline $\mathbf{S 5 5}$ & ZnTe/CdSe & $23 / 12$ & $560 / 490$ & $300 / 420$ & 0.07 \\
\hline S71 & ZnTe/CdSe & $82 / 50$ & $450 / 350$ & $360 / 1800$ & 0.08 \\
\hline S75 & CdTe/CdSe & $65 / 50$ & $400 / 350$ & $45 / 1800$ & 0.14 \\
\hline S79 & CdTe/CdSe & $174 / 50$ & $400 / 350$ & $1200 / 1800$ & 0.40 \\
\hline S82 & ZnTe/CdTe/CdS & $69 / 65 / 31$ & $450 / 400 / 375$ & $300 / 60 / 300$ & $\mathbf{0}$ \\
\hline S83 & ZnTe/CdTe/CdS & $82 / 65 / 31$ & $450 / 400 / 375$ & $360 / 60 / 360$ & $\mathbf{0}$ \\
\hline
\end{tabular}

Table 5.1 Thin Film Semiconductor Device Summary. 
The use of CdTe, CdSe, CdS, and ZnTe as thin film semiconductors in PV solar cell modules is well known and has proved to be economically viable materials for PV module manufacture. However these semiconductors all must have dopants to achieve the efficiencies required for marketable devices $[3,6,10,25,26,27,28,36]$. This research focused on using un-doped Group II-VI compounds to make PV cells, intending to study the feasibility of producing solar cells using a singular technique.

The devices that exhibited the best photovoltaic effects were the $\mathrm{CdTe} / \mathrm{CdSe}$ and the $\mathrm{ZnTe} / \mathrm{CdSe}$ cells. In the case of the $\mathrm{CdTe} / \mathrm{CdSe}$, the results in this research were better by two orders of magnitude than other recent efforts in which these compounds were doped[34], while the results with the ZnTe/CdSe cells were not as impressive as other experimental work with these same semiconductors [32]. The CdS/CdSe and $\mathrm{ZnTe} / \mathrm{CdTe} / \mathrm{CdS}$ cells in this research produced no appreciable PV effects while other groups have had impressive results using these same semiconductors. The difference in their results and ours is due to their introduction of dopants in the various constituent semiconductor thin films and the variety of other deposition methods used.

The data from this research indicates that the photovoltaic effect could be optimized in the CdTe/CdSe devices by increasing the thickness of the depositions. Additionally, annealing may reduce defects and traps, thereby reducing recombination effects and increasing the photocurrent while the use of other materials for the back contact could reduce series resistance. For future research, varying the deposition temperatures to allow for the creation of a $\mathrm{CdS} / \mathrm{CdTe} / \mathrm{ZnTe} \mathrm{PV}$ cell is also a possibility, as well as a PV cell of $\mathrm{CdS} / \mathrm{Cd}_{1-\mathrm{x}} \mathrm{Zn}_{\mathrm{x}} \mathrm{Te} / \mathrm{CdTe}$ or a $\mathrm{Cd}_{1-\mathrm{x}} \mathrm{Zn}_{\mathrm{x}} \mathrm{S} / \mathrm{Cd}_{1-\mathrm{x}} \mathrm{Zn}_{\mathrm{x}} \mathrm{Te}$. There has 
been some use of those ternary compounds in PV cell research long ago [38] and some research on II-VI nanorods [34] but the use of II-VI ternary compound nanowires and II-VI ternary nanodots has not been thoroughly researched and may prove to yield interesting results. 
References

1. International Energy Agency, Key World Energy Statistics, http://www.iea.org (2009)

2. BP Statistical Review of World Energy: Sections 1,6,22,32,36,38,40,44 (June 2009): http://www.bp.com/statisticalreview

3. O'Rourke S., Kim P., Polavarapu H., "Looking Through the Storm," Solar Photovoltaic Industry, Global Markets Research Company, 21 January 2009.

4. Solomon S., Qin D., Manning M., Chen Z., Marquis M., Averyt K., Tignor M., and Miller H. (editors),WG1 The Physical Science Basis, Contribution of Working Group 1 to the Fourth Assessment Report of the Intergovernmental Panel on Climate Change, 2007: Cambridge University Press, Cambridge, UK. And New York, NY USA

5. United States Environmental Protection Agency, Endangerment and Cause or Contribute Findings for Greenhouse Gases under Section 202(a) of the Clean Air Act, December 2009:Climate Change Division, Office of Atmospheric Programs, U.S.E.P.A, Washington, DC

6. Price S., Margolis R., 2008 Solar Technologies Market Report, NREL: United States Department of Energy, January 2010

7. BP Statistical Review of World Energy: Section 2 June 2009, http://www.bp.com/statisticalreview

8. Lorenz P. \& Pinner D. \& Seitz T., "The Economics of Solar Power," The McKinsey Quarterly, June 2008.

9. Pray L., "Powering The World With Sunlight", A White Paper Describing the Discussions and Outcomes of the $1^{\text {st }}$ Annual Chemical Sciences and Society Symposium: Kloster Seeon, Germany July 23-25 2009

10. Birkmire R., Shafarman W., et al, Processing Materials Devices and Diagnostics for Thin Film Photovoltaics: Fundamental and Manufacturability Issues, University of Delaware for NREL: Final Report 1 March 2005-30 November 2008.

11. International Energy Agency-Photovoltaic Power Systems Programme, Trends in Photovoltaic Applications: Survey report of selected IEA countries between 1992 and 2008, Report IEA-PVPS T1-18:2009, http://www.iea.org

12. Mazer J., US. Department of Energy, Solar America Initiative, "Photovoltaic Technology and Recent Developments", Vacuum Technology \& Coating April 2008. http://vactechmag.com

13. http://www.en.wikipedia.org/wiki/Solar_cell

14. Gessert T., Asher S., et al. NREL, "Analysis of CdS/CdTe devices incorporating s ZnTe:Cu/Ti Contact", Thin Solid Films, 5156103 (2007)

15. Potlog T., Ghimpu L., Antoniuc C., "Comparative study of CdS/CdTe cells fabricated with and without evaporated Te-layer", Thin Solid Films, 5155824 (2007)

16. Romeo A., Khrypunov G., et al., "Bifacial configurations for CdTe solar cells", Solar Energy Materials \& Solar Cells, 911388 (2007) 
17. Wolfe, C. \& Holonyak, N. \& Stillman G. (1989). Physical Properties of Semiconductors. Englewood Cliffs, New Jersey: Prentice Hall

18. Nelson J., (2003). The Physics of Solar Cells. London, UK: Imperial College Press

19. Pierret R., (1989),Semiconductor Fundamentals $2^{\text {nd }}$ ed., Reading, Massachusetts: Addison-Wesley Publishing Company, Inc.

20. Overstraeten R., Mertens R., (1986), Physics, Technology and Use of Photovoltaics. Bristol, UK: Adam Hilger Ltd

21. Araujo G., Sanchez E., "A New Method for Experimental Determination of the Series Resistance of a Solar Cell", IEEE Transactions On Electron Devices, 29 1511 (1982)

22. Agarwalt S., Muralidharant R., et al., "A new method for the measurement of series resistance of solar cells", J. Phys. D: Appl. Phys., 141643 (1981)

23. Madelung O., (2003), Semiconductors Data Handbook. Springer-Verlag: ISBN 3540-40488-0

24. Van de Walle C. \& Neugebauer J., "Universal alignment of hydrogen levels in semiconductors, insulators and solutions," Nature, 423626 (2003)

25. Kosyachenko L., Grushko E., Motushchuk V., "Recombination losses in thin-film CdS/CdTe photovoltaic Devices," Solar Energy Materials \& Solar Cells, 902201 (2006)

26. Amin N., et. Al., "Numerical modeling of $\mathrm{CdS} / \mathrm{CdTe}$ and $\mathrm{CdS} / \mathrm{CdTe} / \mathrm{ZnTe}$ solar cells," Solar Energy Materials \& Solar Cells, 911202 (2007)

27. Gayam S., et. Al., "The structural and electrical properties of Zn-Sn-O buffer layers and their effect on CdTe solar cell performance," Thin Solid Films, 5156060 (2007)

28. Reislohner U., et. Al., "Doping profiles in CdTe/CdS thin film solar cells," Thin Solid Films, 5156157 (2007)

29. Hoppe H., et al., J. Mater. Res. 191924 (2004)

30. Rincom M., et al., "Photoelectrochemical behavior of chemically deposited CdSe and coupled CdS/CdSe semiconductor films", International Symposium on Solar Energy Materials, 52399 (1998)

31. Patel N., et al., "Fabrication and characterization of ZnTe/CdSe thin film solar cells", Department of Electronicxs, Sadar Patel University, Gujarat State, India

32. Pal A., et al., "Preparation and characterization of ZnTe/CdSe solar cells", Vacuum, 411460 (1990)

33. Kosyachenko L., et al., "Requirements imposed on the electrical properties of the absorber layer in CdTe-based solar cells", J .Mater Sci: Mater Electron, 181099 (2007)

34. Zhong H., et al., "Synthesis of Type II CdTe-CdSe Nanocrystal Heterostructured Multiple-Branched Rods", J. Phys. Chem. C, 1116536 (2007)

35. Ferekides Chris, "Next Generation CdTe Technology Substrate Foil-based Solar Cells", US DOE Solar Energy Technologies Program Peer Review: Denver, Colorado March 9-10 2009 
36. Trefny J. \& Mao D., "Polycrystalline Thin Film Cadmium Telluride Solar Cells Fabricated By Electrodeposition", Annual Technical Report 20 March 1995- 19 March 1996: NREL for US Dept. of Energy Contract \# DE-AC36-83CD10093 (1997)

37. Armani N., et al., "Role of thermal treatment on the luminescence properties of CdTe thin films for photovoltaic applications", Thin Solid Films, 5156184 (2007)

38. Chu T., et al., "Films and junctions of cadmium zinc telluride", J. Appl. Phys., 71 5635 (1992)

39. Birkmire R. and Meyers P., "Processing Issues for Thin-Film CdTe Cells and Modules", US DOE University Center of Excellence for Photovoltaic Research and Education (NREL) Newark, Delaware: NREL for US Dept. of Energy Contract \#XAV-13170-01 